
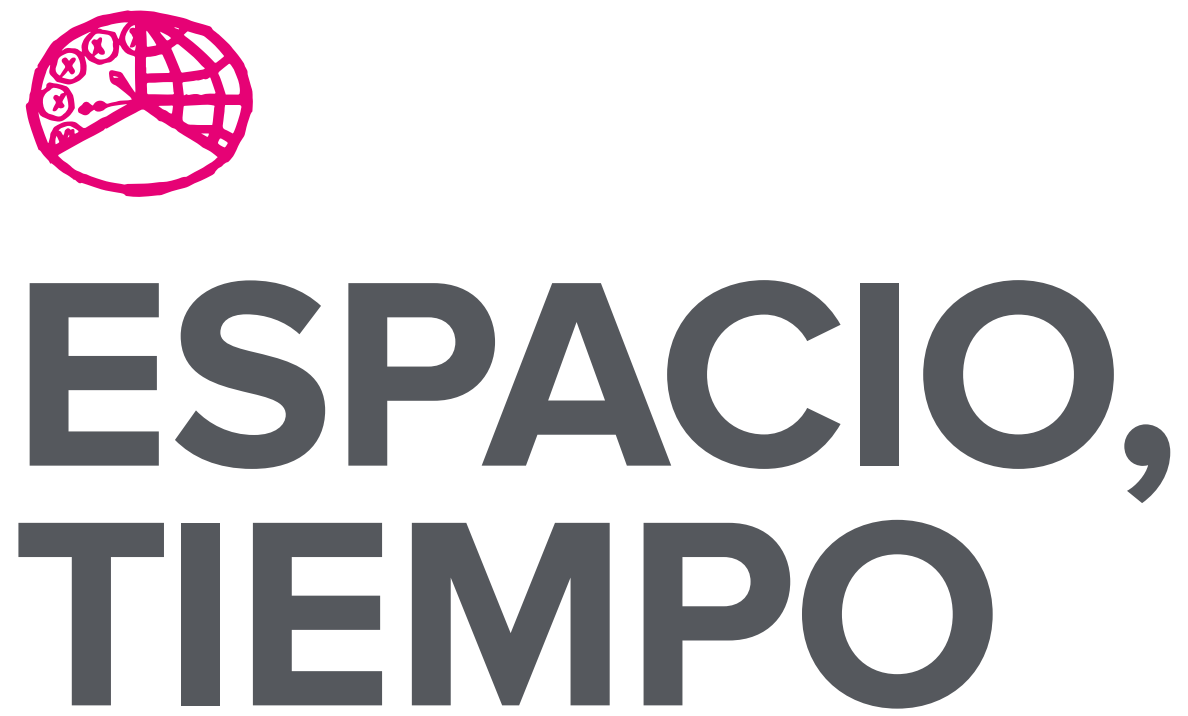

AÑO 2016

ISSN 1131-7698

E-ISSN 2340-1354
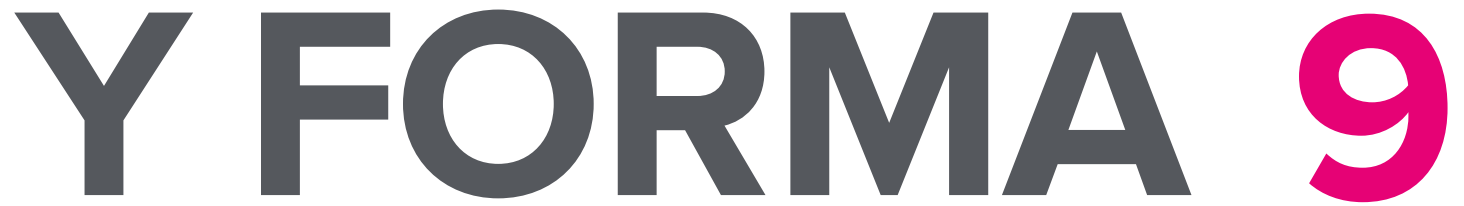

SERIE I PREHISTORIA Y ARQUEOLOGÍA

REVISTA DE LA FACULTAD DE GEOGRAFÍA E HISTORIA 


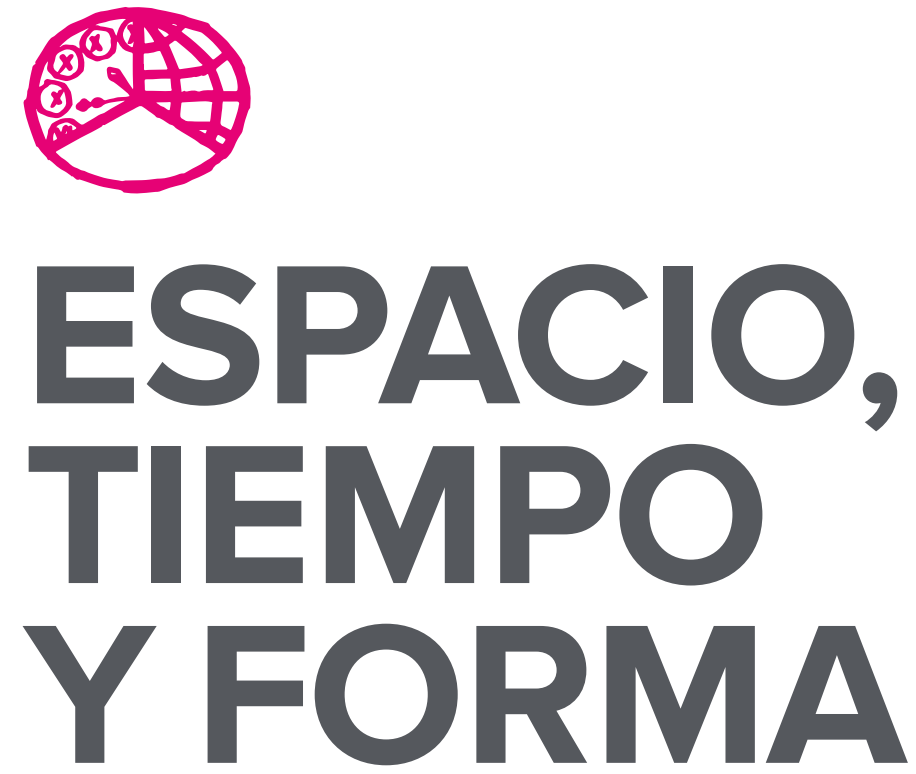

AÑO 2016

ISSN 1131-7698

E-ISSN 2340-1354

SERIE I PREHISTORIA Y ARQUEOLOGÍA

REVISTA DE LA FACULTAD DE GEOGRAFİA E HISTORIA

DOI: http://dx.doi.org/10.5944/etfi.9.2016

\section{UกED}

UNIVERSIDAD NACIONAL DE EDUCACIÓN A DISTANCIA 
La revista Espacio, Tiempo y Forma (siglas recomendadas: ETF), de la Facultad de Geografía e Historia de la UNED, que inició su publicación el año 1988, está organizada de la siguiente forma:

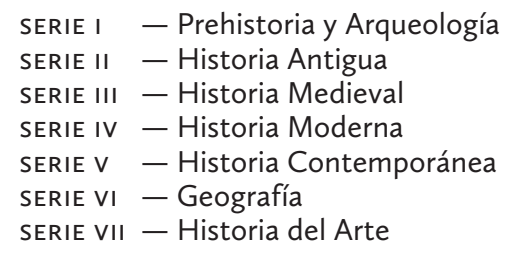

Excepcionalmente, algunos volúmenes del año 1988 atienden a la siguiente numeración:

$$
\begin{aligned}
& \mathrm{N}^{\circ}{ }_{1}-\text { Historia Contemporánea } \\
& \mathrm{N} ._{2}{ }^{\circ} \text { - Historia del Arte } \\
& \mathrm{N} .^{\circ} 3 \text { - Geografía } \\
& \mathrm{N} .^{\circ} 4 \text { - Historia Moderna }
\end{aligned}
$$

ETF no se solidariza necesariamente con las opiniones expresadas por los autores.

Espacio, Tiempo y Forma, Serie I está registrada e indexada, entre otros, por los siguientes Repertorios Bibliográficos y Bases de Datos: LATINDEX, DICE, ISOC (CINDOC), RESH, IN-RECH, DIALNET, E-SPACIO UNED, CIRC 2.0, MIAR 2OI6, CARHUS 2OI4, FUENTE ACADEMICA PREMIER, PERIODICALS INDEX ONLINE, ANTROPOLOGICAL LITERATURE, FRANCIS, ULRICH'S, SUDOC, ZDB, L'ANNÉE PHILOLOGIQUE, DULCINEA (VERDE).

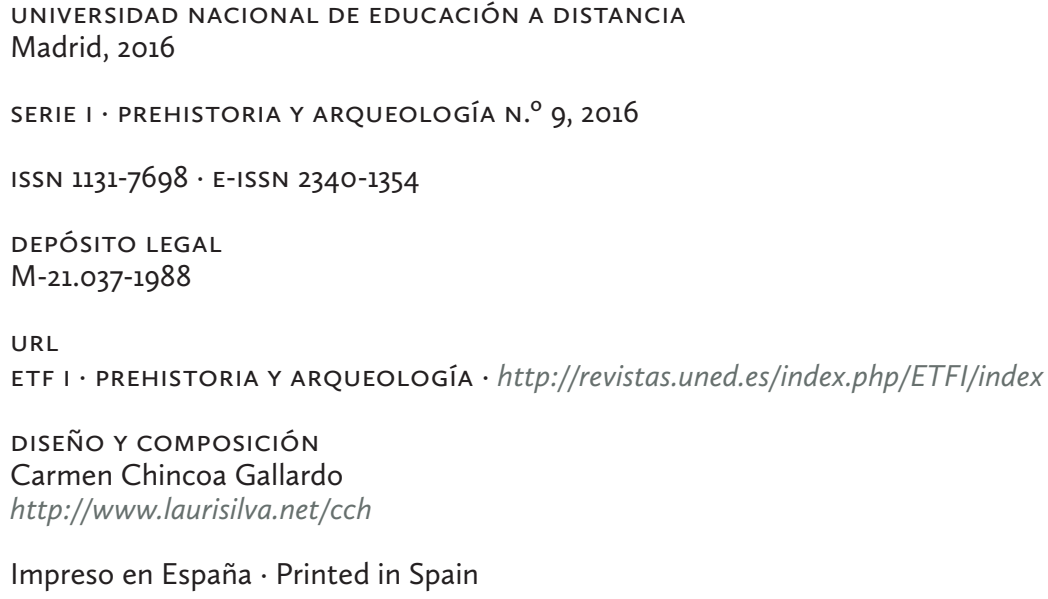




\title{
CONTRIBUCIÓN AL ESTUDIO DE LOS \\ ESPACIOS TERMALES DE AUGUSTA EMERITA: \\ EL BALNEUM DE LA C/ HERNÁN CORTES \\ Y LOS MODELOS DE DOBLE ALVEI
}

\author{
CONTRIBUTION TO THE THERMAL SPACES OF \\ AUGUSTA EMERITA: THE BALNEUM OF C/ HERNÁN \\ CORTÉS AND THE DOUBLE MODELS OF ALVEI
}

\author{
Ana $\mathrm{M}^{\mathrm{a}}$ Bejarano Osorio ${ }^{1}$ \\ Recibido: 28/03/2016 - Aceptado: 30./10/2016 \\ DOI: http://dx.doi.org/10.5944/etfi.9.2016.16218
}

\begin{abstract}
Resumen
La excavación arqueológica realizada en un solar al sureste de la ciudad de Augusta Emerita, ha puesto al descubierto los restos de un complejo de baños privados. Este balneum, del que se ha podido documentar prácticamente su planta completa, se suma a los ya reconocidos en diversas áreas de la ciudad. La particularidad del mismo, radica en la planta sobre la que se desarrolla, siendo el único ejemplo de doble cabecera absidada documentada en Mérida, lo que nos permite establecer una nueva planta para los conjuntos termales de la ciudad.
\end{abstract}

Palabras clave

Augusta Emerita, domus extramuros, muralla, balneum, alvei.

\begin{abstract}
A private thermal complex has recently been found the southeast area of Augusta Emerita. Of this balneum, we have documented the whole building. This finding increases the amount of these structures in this city. The main peculiarity is the plan developed. It is the first time in Mérida that a double apse is located in the emeritense cast of thermal complexes.
\end{abstract}

Keywords

Augusta Emerita, extramoenia house, roman wall, balneum, alvei.

1. Consorcio Ciudad Monumental de Mérida. Correo electrónico: ana@consorciomerida.org 


\section{INTRODUCCIÓN}

Dentro de las labores preventivas que lleva a cabo el Consorcio de la Ciudad Monumental de Mérida, en el año 2009 se realizó una intervención arqueológica en el solar n. ${ }^{\circ} 44$ de la c/ Hernán Cortés ${ }^{2}$, (Figura I).

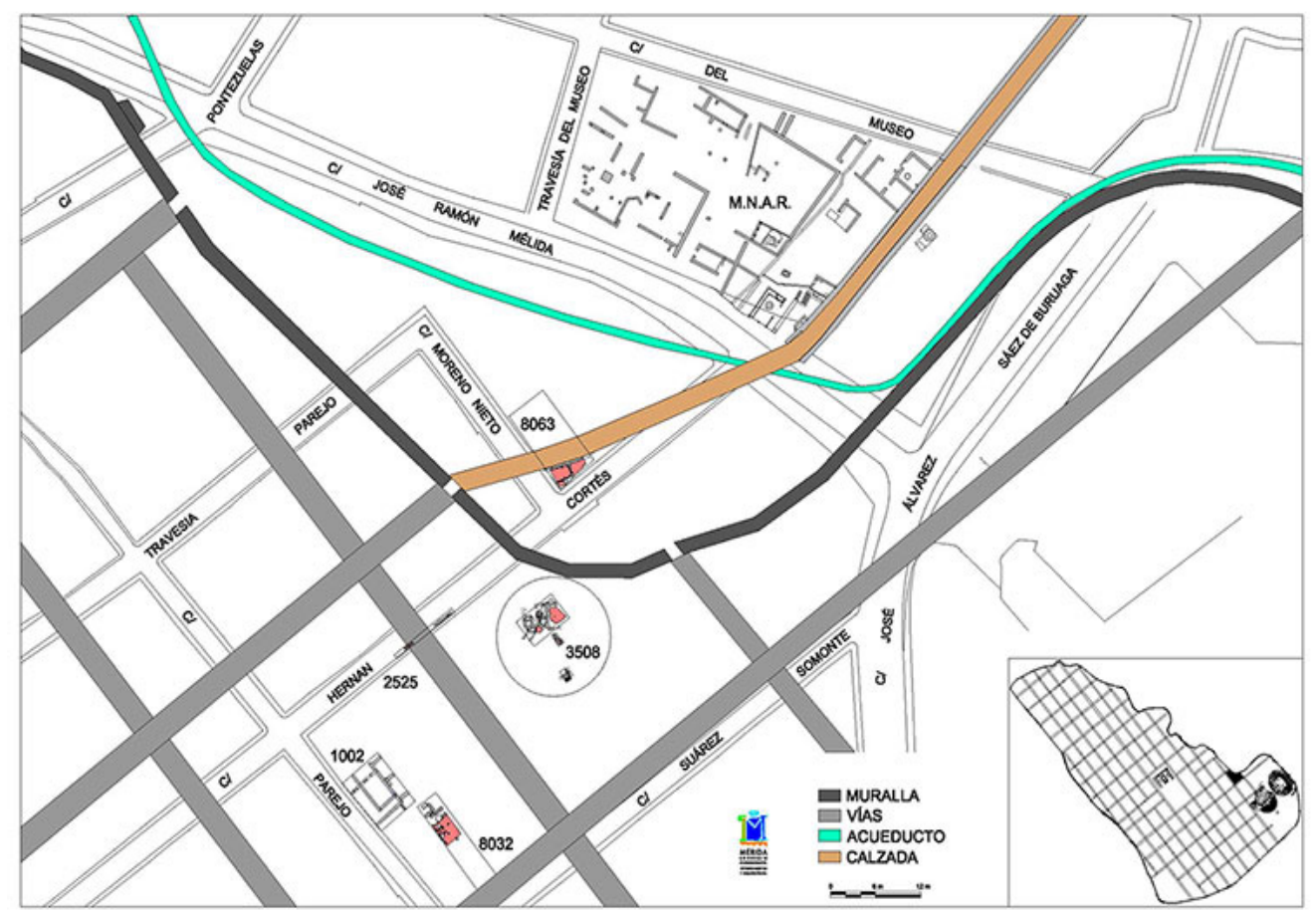

FIG. 1. PLANO GENERAL DE SITUACIÓN DE LOS RESTOS (CONSORCIO DE LA CIUDAD MONUMENTAL DE MÉRIDA)

Dicho predio se ubica intramuros de la Colonia Augusta Emerita si nos atenemos, en principio, al trazado actual asignado a la muralla romana. En concreto, se localiza en una de las areae limítrofes con la cerca altoimperial, que se ha querido identificar

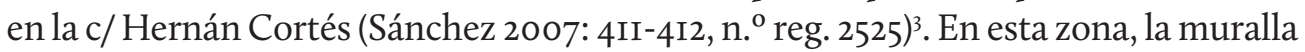
presenta un acusado quiebro para adaptarse a las curvas de nivel y englobar, de este modo, a los edificios públicos de ocio y representación: el teatro y el anfiteatro.

El urbanismo de esta parte suroriental de la ciudad romana se conoce relativamente bien gracias a las continuas intervenciones arqueológicas llevadas a cabo en la zona con mención especial a las realizadas por el Consorcio de Mérida a lo largo de estos últimos años. En un repaso a las mismas, comenzamos por las domus actualmente visibles en la cripta del Museo Nacional de Arte Romano, casas fechadas en el s. I d.C. y abandonadas en el s. IIl d.C. (Sánchez y Nodar I997: 374-376).

2. Este solar se sitúa en la Zona II, según el PGOU de Mérida. Dado su enorme interés científico, tras el preceptivo seguimiento de obras, se dictaminó su excavación parcial que se centró en el área central del patio de la actual vivienda. Por todo ello, la documentación obtenida resulta incompleta.

3. En dicha intervención, los vestigios exhumados fueron interpretados por su excavador como los posibles restos de la muralla romana (una torre), a los que se vinculó un pavimento de opus signinum. 
Por proximidad con nuestra área de estudio, hemos de citar en primer lugar la excavación llevada a cabo en el inmueble $n^{\circ} 37$ de la citada c/ Hernán Cortés. En ella se documentaron los restos de una domus extramuros fechada a mediados del s. I d.C., en la que se pudo reconocer la zona central de un magnífico peristilo y uno de los muros de cierre. Cancelada esta vivienda y con una acusada elevación de la cota de uso, se construye una segunda casa datada en el siglo IV d.C. Dicha domus se orienta siguiendo un camino de nueva creación que enlaza la zona extramuros con la puerta existente en esta parte del lienzo amurallado. Los resultados obtenidos en esta excavación arqueológica son los que han posibilitado retranquear en parte el recorrido de la muralla por este sector. De ser así, el perímetro amurallado sería ligeramente más reducido al difundido por la historiografía tradicional (Bejarano 2007: 248-250, figs. I7 y I8, n. ${ }^{\circ}$ reg. 8063).

Intramuros de la Colonia, hay varias excavaciones que nos informan del desarrollo de las viviendas situadas en la proximidad de la muralla, por cuanto ocupan las manzanas cercanas a los límites de la ciudad. Son diversas las construcciones domésticas que se han reconocido, citando como muestra y por su vecindad, las intervenciones de la c/ Suárez Somonte (Méndez 2004: 257-267, n. ${ }^{\circ}$ reg. 8032) y de la c/ Parejos (Barrientos 2000: 22I-275, n. ${ }^{\circ}$ reg. I002).

En la primera, el solar de la c/ Suárez Somonte, se constató una fase ocupacional fechada en el s. I d.C. en la que se identificaron tres habitaciones asociadas a un corredor de acceso cuya orientación venía impuesta, obviamente, por el trazado viario existente. La estancia principal fue reformada en el s. III d. C., con la colocación de un nuevo pavimento de mosaico, donde aparecen representadas escenas geométricas y una perdiz, por lo que se ha interpretado como un posible triclinium (Méndez 2004: 262-264).

Por otro lado, en el solar de la c/ Parejos se excavó una domus de la que se documentaron cinco estancias cuyos usos, debido a la parcialidad de los datos, resultan de difícil interpretación. Una de ellas estaba construida con un muro doble que soportaría un segundo piso en altura. La decoración del conjunto permite, por paralelos, datarlo en el s. I d.C. Varias reformas, a lo largo de la época bajoimperial y tardoantigua, modificarán parcialmente la edificación, pero en ningún caso variando con ello la orientación de los nuevos muros que continúan rigiéndose por el cardo y decumanus minor que delimitan la manzana (Barrientos 2000: 247-256).

\section{LA VIVIENDA Y LOS BAÑOS}

La excavación arqueológica realizada en el inmueble $n .^{\circ} 44$ de la c/ Hernán Cortés, se ha centrado básicamente en los espacios correspondientes al patio y las salas posteriores de la casa contemporánea. Los resultados arqueológicos nos han permitido vincular los restos exhumados a una construcción doméstica y unos baños, cuya documentación ha estado condicionada por lo limitado de la intervención.

Referido a la domus, el registro, muy parcial, se concreta en la identificación de varios muros que delimitan diversas estancias, parte de una estructura absidada y 
un pavimento musivo. Junto a estos muros y niveles de pavimentación se reconoce el baño, ampliamente documentado en casi la totalidad de su planta, un conjunto que por sus características y dimensiones determinamos como de carácter privado. La particularidad del mismo radica no sólo en su estructuración, disposición y cronología, aportando datos nuevos al conocimiento de los espacios termales emeritenses, sino que su ubicación transciende al conocimiento de este sector de Augusta Emerita.

En función de los datos arqueológicos conocidos podemos establecer, al menos, dos fases de ocupación. La primera está definida por una cimentación a la que se adosan dos suelos que pavimentarían sendas dependencias. Una, la situada al sursureste, con un pavimento de opus signinum y la otra, al norte-noroeste con un piso probablemente también de opus signinum, a juzgar por los fragmentos aparecidos en los niveles de destrucción, pero del que sólo se ha conservado una lechada de mortero de cal.

La parcialidad de los restos excavados imposibilita cualquier interpretación funcional. Estratigráficamente estas dos habitaciones no guardan relación con el espacio de baños. Son simplemente estancias situadas en esta zona de la domus que fueron posteriormente amortizadas. El material procedente de la destrucción del muro intermedio así como de los suelos, sumados a los aportes de tierra de otros lugares, se utilizó como relleno sobre el que elevar el terreno y asentar el pavimento de una de las salas del balneum.

Es la segunda fase ocupacional la que ya está directamente relacionada con la construcción del conjunto balnear.

\section{I.1. EL BALNEUM}

El balneum es un edificio conformado por una serie de espacios bien definidos, dispuestos en batería y orientados este-oeste, estableciendo la clásica secuencia termal de apodyterium/:frigidarium?, tepidarium y caldarium, de planta lineal simple y de recorrido retrógrado. Su ubicación al sur y la disposición de las salas nos remiten a las prescripciones ofrecidas por Vitrubio $(5$, Io) (Figura 2 a y b).

A estas tres estancias, como hemos indicado, se le suma una cuarta, ubicada en el lado norte del ambiente identificado como apodyterium. Pese a que su visibilidad es incompleta, se ha podido documentar su pavimentación de opus signinum provista de cuarto de bocel que se localiza a $20 \mathrm{~cm}$ por encima del suelo de la estancia contigua, una sala que podemos definir, a falta de datos concretos, como una estancia de la domus que conectaría ambas dependencias.

Como decimos, tal vez desde esta sala se accediera al baño y por lo tanto a la primera de las habitaciones del circuito termal, el apodyterium (Ap). Éste, del que son visibles solamente $\mathrm{I} 8 \mathrm{~m}^{2}$, presenta morfología rectangular y accesos en los lados norte y noroeste, conectándola con la siguiente estancia. Su pavimento es de opus signinum y presenta un orificio central. Este suelo hidráulico no llega a adosarse a los muros que delimitan la habitación al norte y al oeste, sino que finalizan a 47 


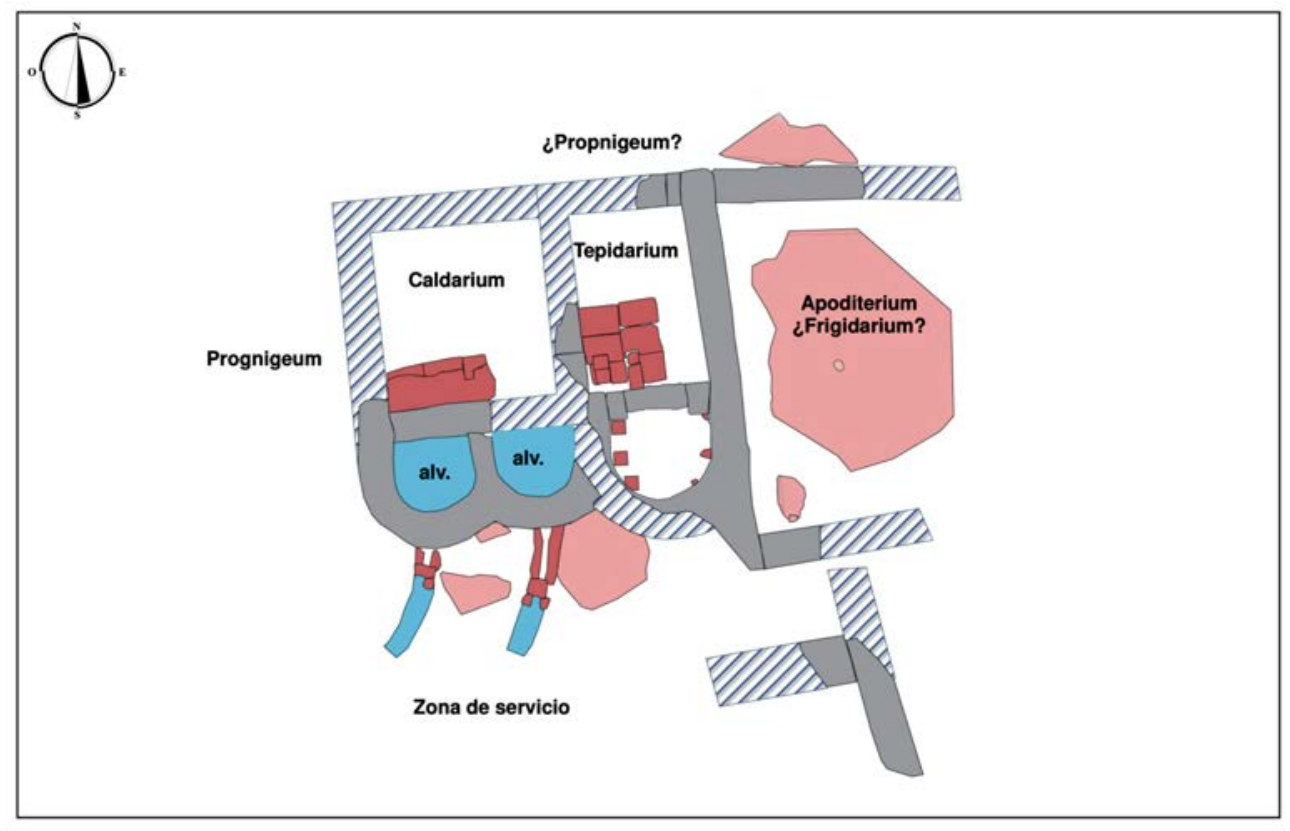

FIG. 2A. PLANO DE RECONSTRUCCIÓN DE LOS BAÑOS. (Fotografía de la autora).

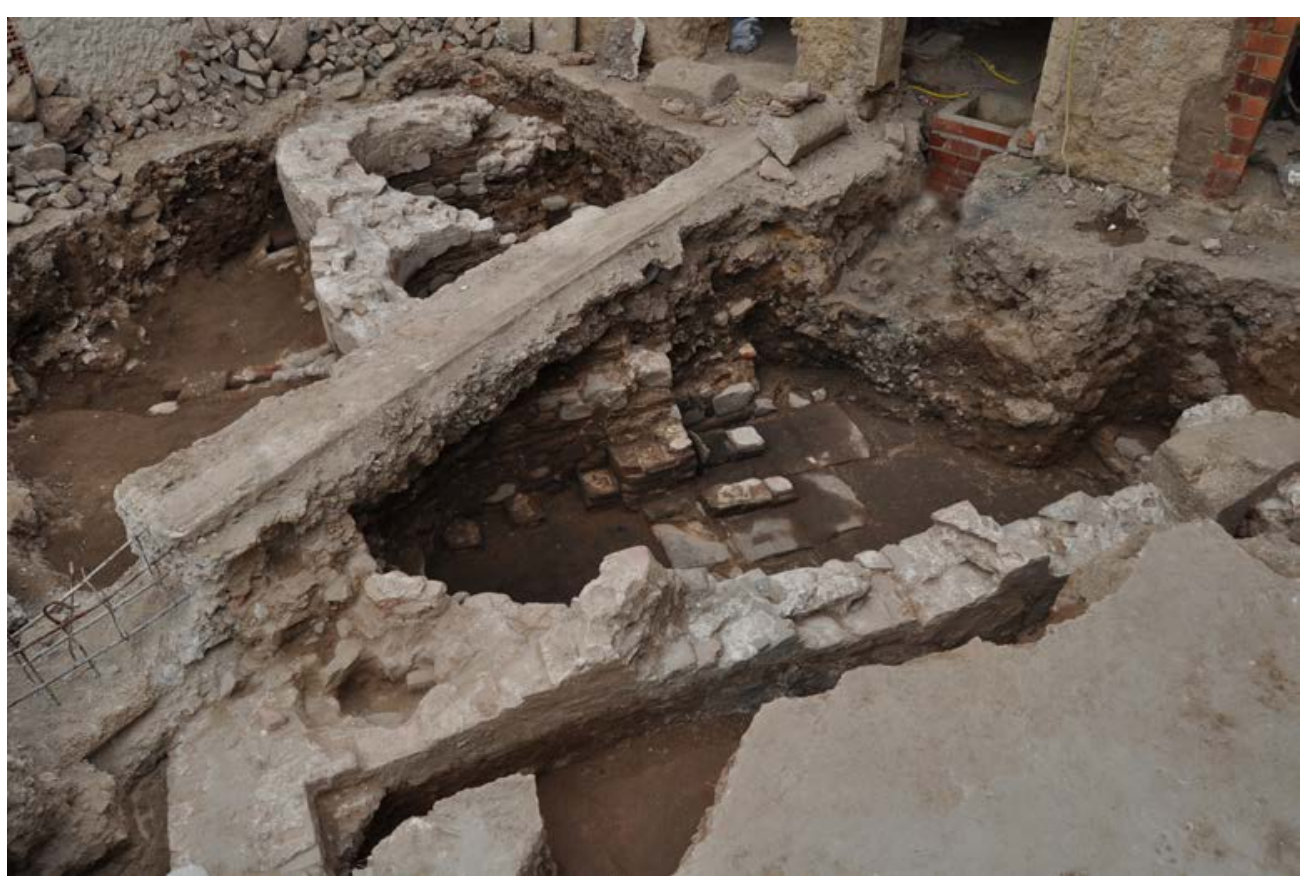

FIG. 2B. VISTA GENERAL DE LA EXCAVACIÓN. (Fotografía de la autora).

$\mathrm{cm}$ de éstos, con unas fragmentadas molduras en cuarto de bocel que marcan unos posibles bancos o escalones actualmente inexistentes (Figura 3).

Se desconoce si esta habitación tuvo una doble función como apodyteriumfrigidarium (Ap-Fr), al no haberse podido localizar en la zona intervenida ninguna piscina o área anexa destinada al baño frío. No obstante, hacia el sur, se observa cómo el cierre se relaciona con otros muros desarrollados en ese lado mostrándonos, 


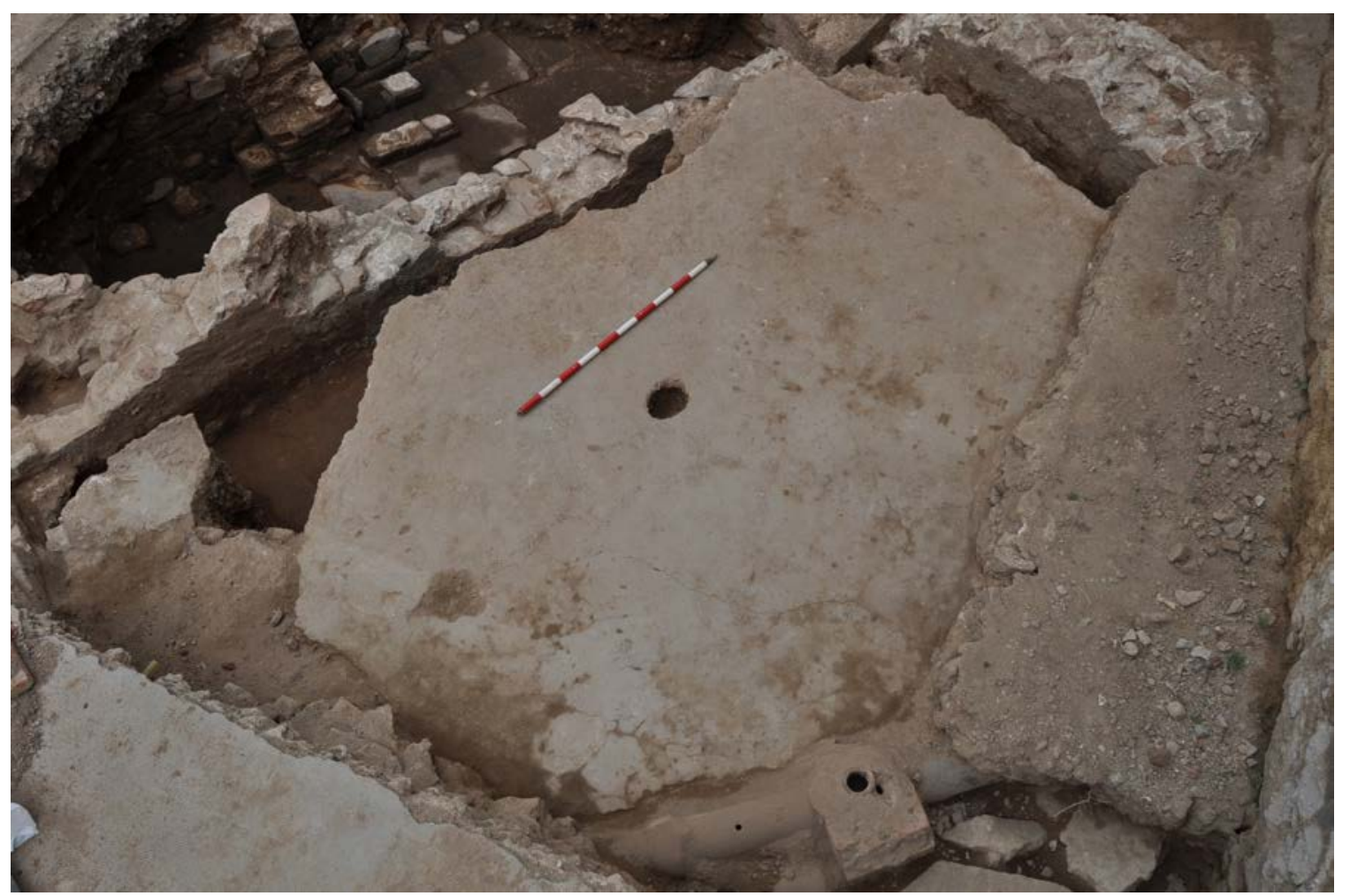

FIG. 3. SALA PRIMERA O APODYTERIUM. (Fotografía de la autora).

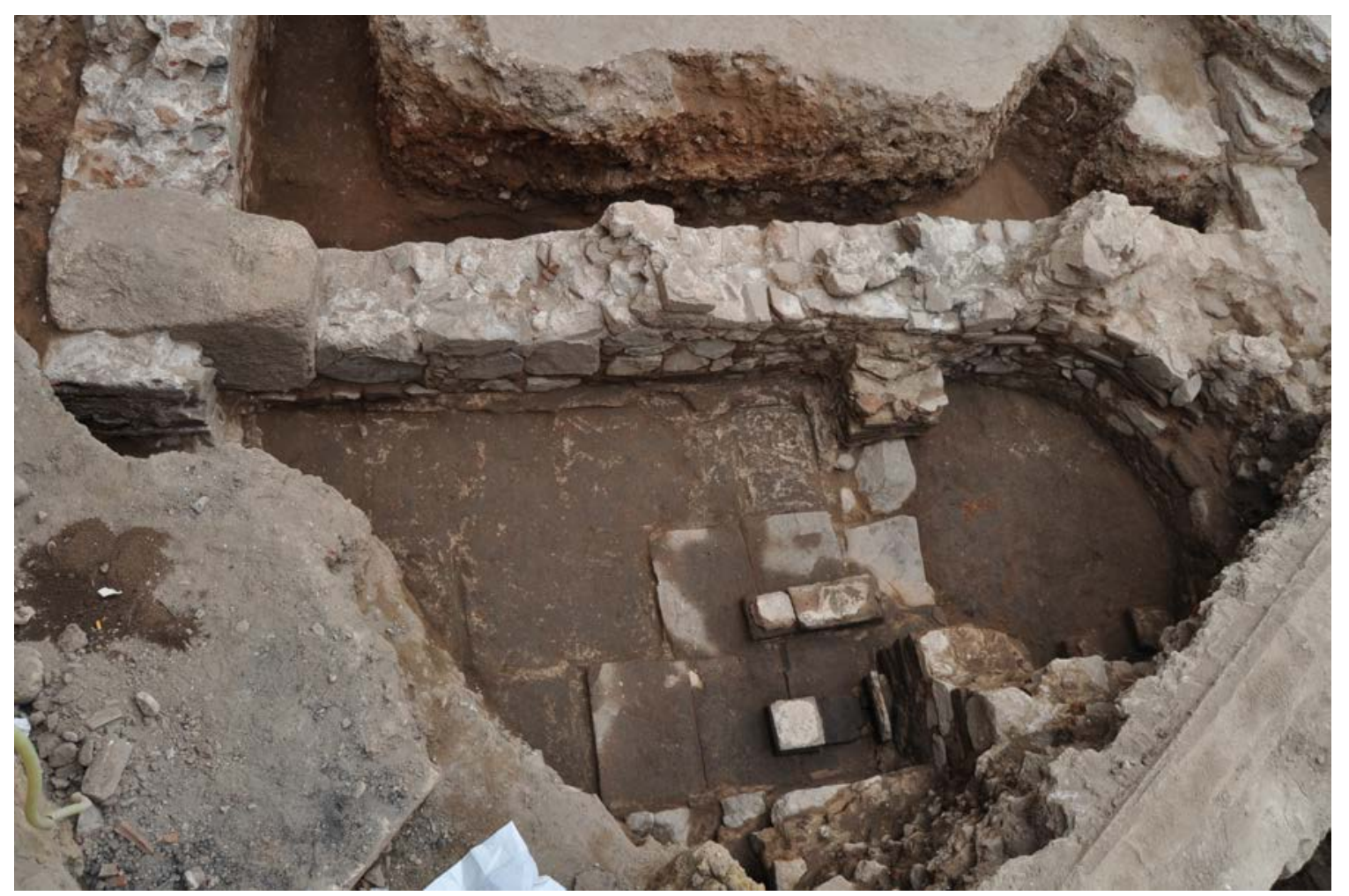

FIG. 4. SALA SEGUNDA O TEPIDARIUM. (Fotografía de la autora). 
por tanto, la existencia de más ámbitos meridionales, por lo que no se descarta un mayor desarrollo en planta que sitúe a la piscina en este lugar.

Desde esta estancia, continuando el recorrido termal, se ingresaba mediante un acceso a la segunda de las salas que identificamos como el tepidarium (Tp), habitación de planta rectangular rematada al sur con un ábside. Sus dimensiones internas son 6'6o $\mathrm{m}^{2}$ aproximados (Figura 4).

Su nivel de tránsito estaría calefactado por un sistema de hypocaustum del que se han podido verificar parcialmente algunos restos de las arquerías de ladrillos. Éstas apoyan sobre un «suelo» hecho con tegulae invertidas asentadas sobre una lechada de mortero de cal, que presentan cierto escalonamiento en los laterales de los muros.

De las tegulae empleadas, sólo 5 están in situ y completas y otras dos fragmentadas, contabilizándose un total de I8, cuyas improntas han quedado en el mortero de argamasa. Todas presentan una superficie enormemente desgastada por la acción continuada del fuego. Se disponen «a soga», paralelas al cierre de la estancia orientado oeste-este, y con una cierta inclinación hacia el muro a los pies de la sala. Es en este muro septentrional donde se documenta parcialmente un vano que evidencia la presencia de alguna estancia o espacio de servicio, un posible praefurnium.

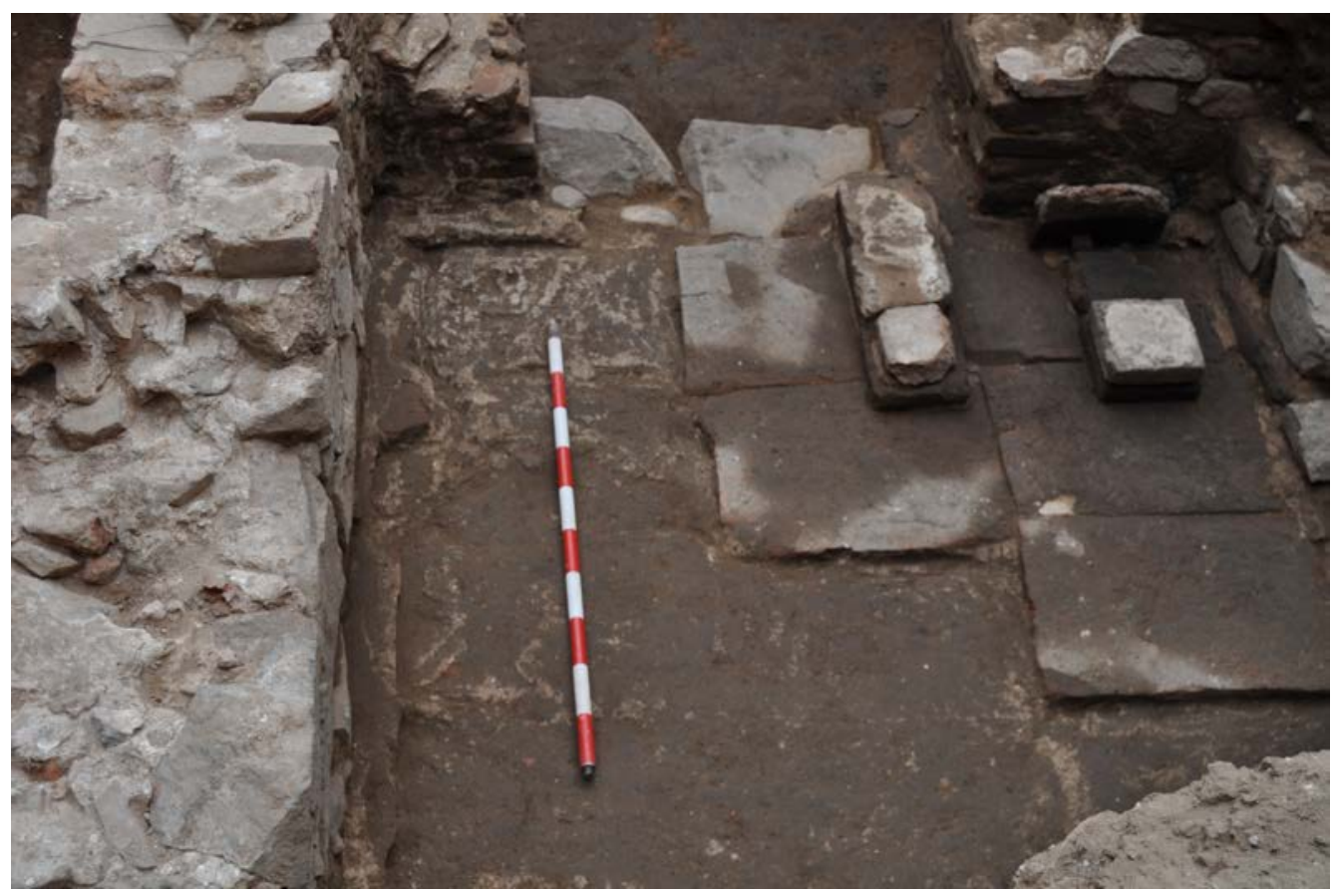

FIG. 5. DETALLE DEL NIVEL DE PAVIMENTACIÓN DEL TEPIDARIUM. (Fotografía de la autora).

La suspensura conserva parte del arranque de la arquería, alineada norte-sur y elaborada con ladrillos superpuestos trabados con cal, con una equidistancia entre ellas de $27 \mathrm{~cm}$, (Figura 5).

La zona de la cabecera, recordemos absidada, está igualmente calefactada con arquería latericia, en este caso dispuestos de forma transversal respecto a los anteriores y con separaciones adaptadas a la curvatura del ábside. En su interior, 
se han documentado in situ tres de estos arranques y la impronta de los otros tres apoyos. A diferencia de los anteriores, las pilae de esta cabecera asientan sobre una torta de cal de I' $5 \mathrm{~cm}$ de espesor medio, que apoya directamente sobre la roca. Los ladrillos son bessalis y sus caras, totalmente ennegrecidas, nos muestran nítidamente su continuada exposición al fuego.

El tercer ámbito, el caldarium o sala caliente (C), constituía el final del circuito termal. Del mismo se ha excavado parcialmente la sala y la totalidad del remate de su cabecera. Se trata de una estancia de planta rectangular que se cierra en una cabecera doblemente ábsidada, correspondiendo con dos espacios para los baños -alvei-. Las dimensiones totales, en función de la reconstrucción de su planta, establecen un espacio de uso de Io'34 $\mathrm{m}^{2}$, aproximadamente (Figura 6).

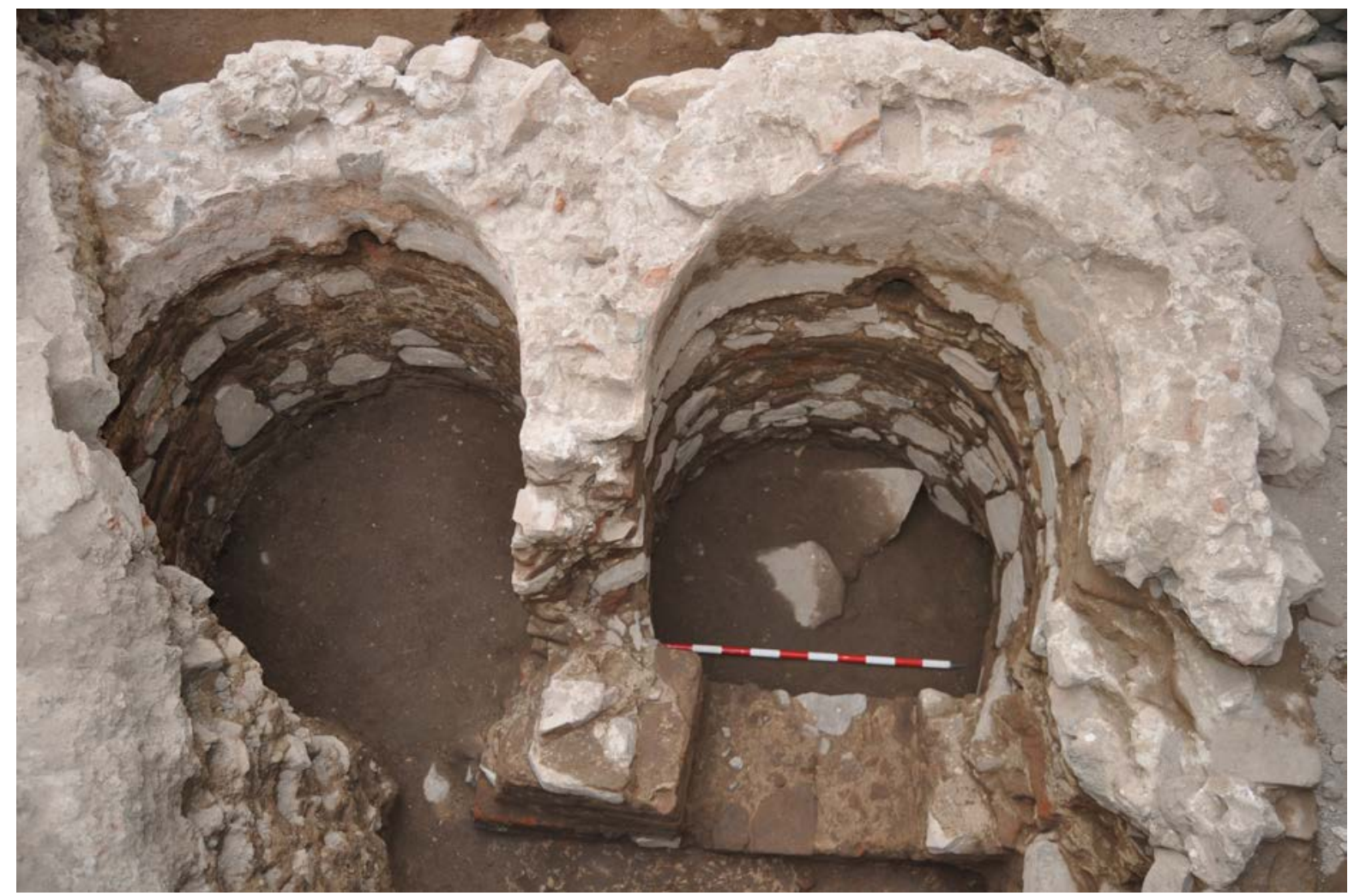

FIG. 6. DETALLE DE LA CABECERA ABSIDADA DEL CALDARIUM. (Fotografía de la autora).

La comunicación de esta habitación con el tepidarium se realiza a nivel inferior a través de un vano situado en el muro intermedio, paso de calor de una sala a otra.

Iniciando la descripción de su cabecera, comenzamos por el ábside ubicado al suroeste, con un diámetro interior de I'15 $\mathrm{m}$ y una altura conservada de I' $57 \mathrm{~m}$. Está revocado por un capa uniforme de opus signinum, revestimiento en el que no se aprecian refracciones, que se ha conservado en una altura máxima de $47 \mathrm{~cm}$, marcando la línea de corte de una posible moldura de cuarto de bocel. En posición centrada se encuentra el orificio de desagüe, tosco canal de mortero de cal que está cajeado con ladrillos (Figura 7). 
Unido a éste ábside, al sureste se desarrolla otro similar que a su vez traba con el cierre del tepidarium, estableciendo la coetaneidad edilicia de todo el conjunto balnear. Éste, presenta una técnica constructiva semejante al anterior, con muros de $45 \mathrm{~cm}$ de anchura, diámetro interior de I's4 $\mathrm{m}$ y una altura conservada de I'26 m. Aparece igualmente revocado por una lechada de opus signinum que define la línea de una posible moldura actualmente inexistente. En una posición prácticamente centrada se sitúa igualmente el orificio de desagüe que muestra un engrosamiento de la capa de opus signinum, revoco en torno a él.

Ambos orificios de drenaje vierten hacia el exterior, siendo recogidas las aguas en sendos canales de ladrillo que se dirigen hacia el suroeste.

Del área correspondiente a la sala no podemos decir mucho, ya que ésta ha sido parcialmente documentada al insertarse en los perfiles del corte. Su nivel de pavimentación está realizado igualmente con tegulae sobre lechada de mortero de cal como cama de cimentación, colocadas en paralelo al muro norte. Presentan una superficie muy degradada sirviendo de apoyo a las pilae para la suspensura. Los materiales constructivos,

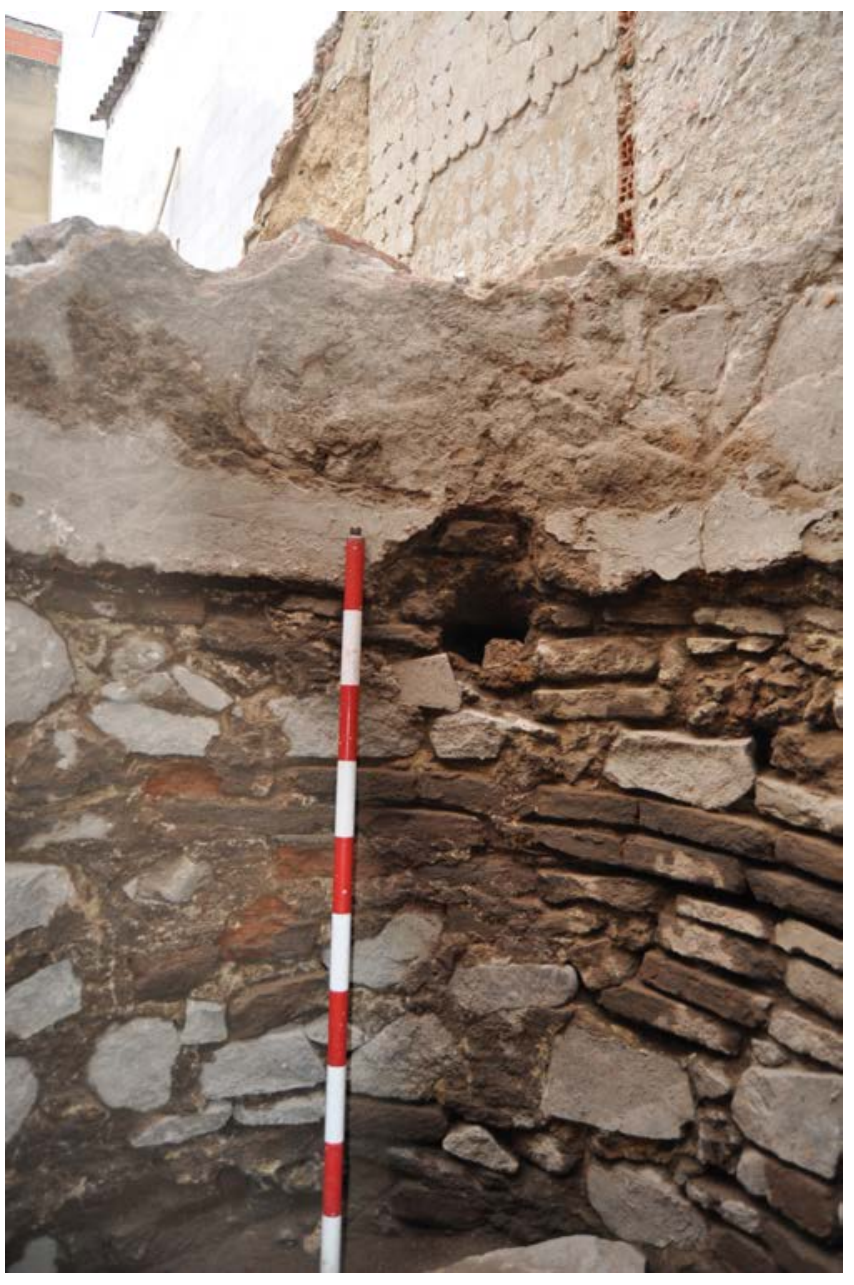

FIG. 7. ALZADO DE LOS ALVEI DEL CALDARIUM. (Fotografía de la autora). hallados en los niveles de amortización, nos permiten suponer un sistema de arcos en paralelo a la sala templada, realizados con bessalis.

La zona de alimentación, es decir, el horno que calefactaría esta sala e indirectamente la habitación templada, se situaría en la parte occidental. En este muro observamos una apertura que indicaría la embocadura del praefurnium, en eje con el vano de comunicación de esta sala con el tepidarium y en relación con la disposición de las arcadas de ladrillos, favoreciendo el paso de calor de una habitación a otra.

$\mathrm{Al}$ exterior, en la cabecera, nos encontramos un muro de cierre y parte de una superficie muy poco regularizada de un tosco mortero de opus signinum que amortizaba los canales de drenaje, y constituía el nivel de uso de una posible área de servicio (Figura 8). 


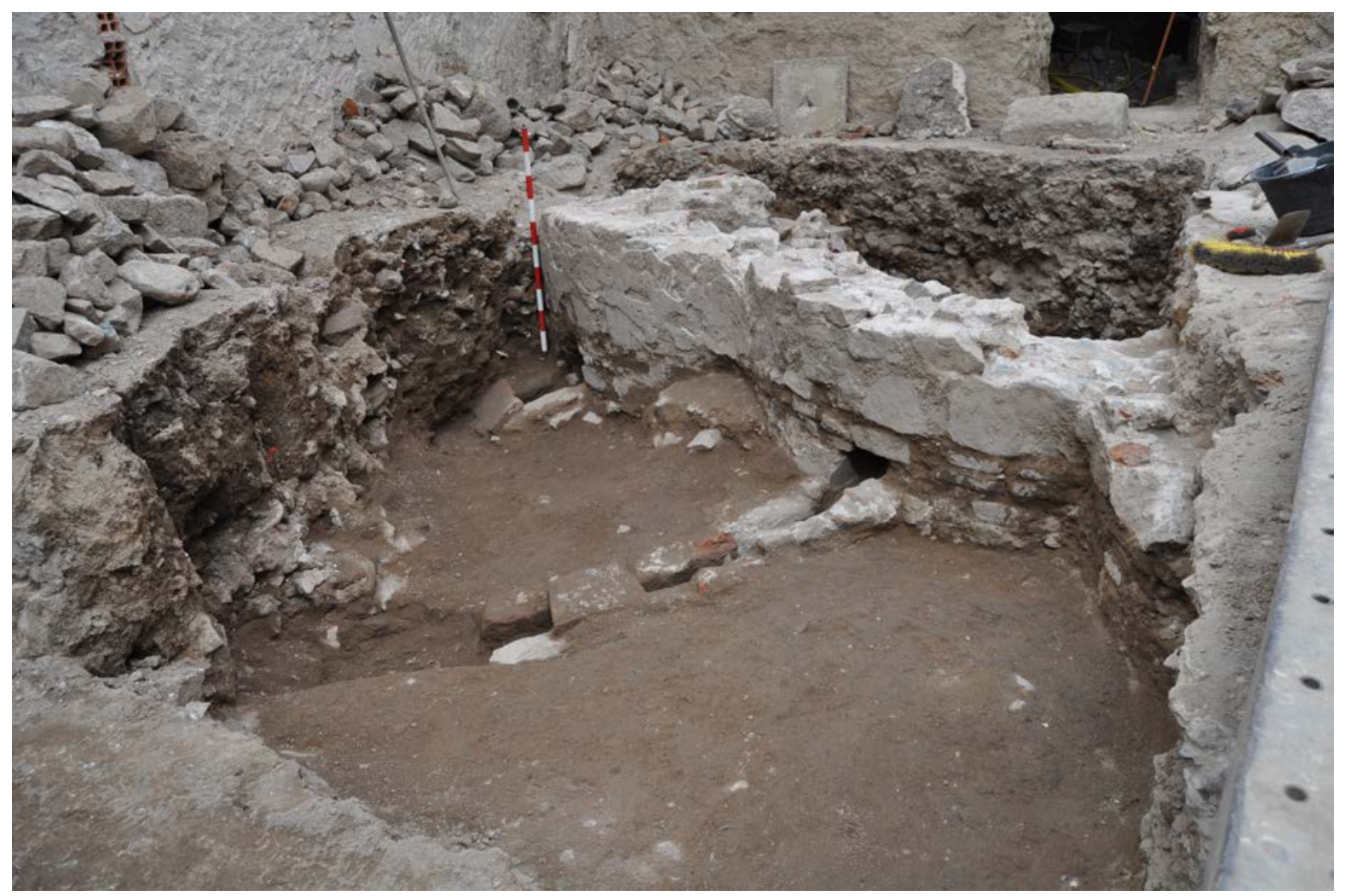

Fig. 8. Detalle de los suelos exteriores y de los CANALes de desagüe del CALDARIum. (Fotografía de la autora).

\section{EL BAÑO: DESARROLLO Y PARALELOS}

Con todos estos datos, podemos definir el conjunto excavado en este solar emeritense como un balneum (Nielsen I993: I2O-I2I; Yegül 20IO: 48-49). El edificio formaría parte de los diversos ambientes que conformaban una domus de la que se conservan escasos vestigios, limitados únicamente a varios muros que se desarrollan hacia el límite al sureste del solar, definiendo estancias con suelos de opus signinum en las que se aprecian diversas refacciones, el arranque de lo que parece ser un espacio absidado ¿triclinium? y parte de una estancia pavimentada con mosaico bicromo ${ }^{4}$. Los paralelos a este mosaico los encontramos en la casa de la c/ Moreno de Vargas (Álvarez I990: I08, lám. 54 A), fechado estilísticamente en el s. IV d.C. e igualmente aparecen identificados en otros espacios de la ciudad, con ligeras variantes, como en la c/ Pedro M. ${ }^{a}$ Plano (s. II d.C.) o en la Casa del anfiteatro (s. III d.C.), todos ellos asociados a pasillos o zonas marginales de las casas (Blanco I976: 33, lám. 67; ibid 1978: 33, lám. 67).

4. El pavimento musivo se caracteriza por la presencia de una banda exterior de cuatro paños, una de teselas rojas de 6'5 cm (incompleta) - teselas blancas de 10' $5 \mathrm{~cm}$ - teselas rojas de $10^{\prime} 5 \mathrm{~cm}$ y banda negra de $2^{\prime} 5 \mathrm{~cm}$, que da paso al motivo principal de cuadrados en punta y círculos tangentes decorados en el interior con cruces de malta en rojo y con tabas negras en los espacios intermedios. 
Respecto a su ubicación dentro del entramado urbano de Augusta Emerita, surgen dudas e interrogantes concernientes a su localización intramuros o extramuros, dado que el recorrido de la muralla romana en este sector de la ciudad no está del todo claro.

En este sentido, atendiendo a la ortogonalidad de la Mérida romana, observamos cómo todas las viviendas intramuros conocidas estructuran y orientan sus plantas en función de los cardines y decumani. No es el caso para la disposición de los muros que articulan este complejo, así como aquellos que asociamos a la domus, muros que presentan una orientación que sigue la traza de la cercana casa romana excavada en el solar de esta misma calle. Esta casa, surgida durante el bajoimperio sobre los vestigios de otra precedente datada en el s. I d.C., fue situada en su día fuera de la cerca amurallada romana aunque muy próxima a ella (Bejarano 2007: 250-252), por lo que proponemos que tanto esta nueva domus como su balneum, se localizaría igualmente extramuros de la Colonia.

Así, tanto las estancias como los distintos niveles de pavimentación de la casa y el baño, engrosaría el catálogo de viviendas extramuros, sumándose a las ya conocidas en esta parte de la ciudad. Estas domus irían ocupando el espacio periférico del pomerium, concretamente la margen izquierda de un camino, bajoimperial, que comunicaba la Colonia con el área suroriental extramuros 5 .

Pese a la escasez de datos materiales que posibiliten conocer la evolución del conjunto, son varios los aspectos que pueden ayudar a establecer una secuencia temporal del mismo. Primeramente, centraremos nuestra atención en las dos estancias previas pertenecientes a la casa que fueron amortizadas para la construcción de este balneum. No hay datos para determinar su cronología absoluta, pero sí es indudable que este conjunto termal fue el resultado de una reforma y/o ampliación que cancela habitaciones de la domus primigenia, para dotarla de baños privados.

En este aspecto, sería un ejemplo más del auge sustancial de los complejos termales surgidos en distintas viviendas emeritenses del s. IV d.C., hecho por otra parte lógico si tenemos en cuenta, para esta época, el estatus de Augusta Emerita como capital de la Diocesis Hispaniarum. Esta capitalidad redundó en un enorme auge social y económico, que tuvo su relejo en la edilicia de la ciudad a todo lo largo del s. IV d.C. (Perich i Roca 20I4: 83-9I; García-Entero 2005: 3I-32 y 62-72; Alba 2004: 77-8I). En este momento, las termas dentro de las viviendas, incorporadas como nuevos espacios o bien ampliadas o reestructuradas, son el elemento de representación evidenciando la importancia del propietario de la domus (GarcíaEntero 2008: 254-258).

En segundo lugar, en relación a la perdurabilidad de estos baños poco se puede determinar. Atendiendo al escaso registro arqueológico, únicamente podemos establecer, grosso modo, una etapa de abandono a la que sucedería la ocupación de la zona en época emiral (s. IX), con la conversión o reutilización de los alvei del

5. La situación extramuros o intramuros de los restos exhumados requiere de un análisis en profundidad que dista de lo pretendido en este artículo. Por ello, nos remitimos a posteriores estudios que seguirán la línea de trabajo esbozada. 
caldarium como improvisados silos de almacenamiento y/o basureros (Malalana et alii 2013: 337-352).

Centrándonos en el balneum, su fisonomía nos remite a estas pequeñas instalaciones de «ocio y representación» que tenían por objeto satisfacer las necesidades de los moradores de la domus. Este carácter privado parte de su inserción arquitectónica en el entramado de la casa y se refleja en el recorrido efectuado por el bañista, que responde a una traza lineal simple retrógrada, el circuito más sencillo documentado en numerosos baños domésticos en nuestra ciudad (Barrientos i997: 267; García-Entero 2005: 524), prolongándose, en la mayoría de los casos, hasta finales del s. Ill d.C. o inicios del s. IV d.C. (García-Entero 2005: 524; Barrientos 2OII: 339).

Como muestra, en Augusta Emerita tenemos el baño de la Casa de los mármoles en el Área Arqueológica de Morería que presenta, en una segunda fase constructiva, una primera sala que funciona como apodyterium/frigidarium provista de una pequeña bañera trilobulada (que invade parcialmente el decumanus minor colindante), y dos bancos corridos adosados a sendos muros, seguida de tepidarium y caldarium al que se anexa la zona de servicio (Alba 1997: 39I-394, lám. 2 y 3; Reis 2004: 79-80, fig. 28; García-Entero 2005: 538-54I, fig. I59). Este balneum se asigna a una reforma realizada en la casa datada entre finales del s. IIl e inicios del s. IV d.C.

Otro ejemplo emeritense de recorrido lineal simple es el baño de la Casa del anfiteatro, con una estancia inicial (frigidarium) provista de dos piscinas que dan paso a dos salas, la primera, de menores dimensiones, que facilita el tránsito a una segunda más amplia, ambas identificadas como tepidaria, y que finalizan en el caldarium con alvei en la cabecera (García-Entero 2005: 549-552, fig. I62).

Una reciente publicación de una villa periurbana provista de un espacio termal, nos muestra otro ejemplo de baño doméstico donde se reconoce un apodyterium/ frigidarium, que da paso a un tepidarium y caldarium, siguiendo un modelo lineal, baño datado en el bajoimperio (Méndez 2015: 66-74)

Prosiguiendo con nuestro conjunto termal, y atendiendo a la ordenación de las estancias excavadas, el bañista iniciaba su rutina diaria en el apodyterium, dependencia que, para este caso, no podemos concluir con datos si correspondía con el modelo apodyterium/frigidarium o simplemente apodyterium. No obstante, y en función del registro arqueológico, parece más que posible la presencia de una piscina que se abriría hacia el sur del apodyterium. Ambos espacios formarían parte de un primer bloque termal de notables dimensiones, en consonancia con la monumentalidad y amplitud que adquieren los espacios fríos a partir del s. III d.C. Estas habitaciones, son las que simbolizaban en mayor medida la importancia de las termas como «escenario de recepción y reunión.» (García-Entero 2008: 263-265).

En base al registro arqueológico, se puede definir como una habitación de planta rectangular con bancos corridos, al menos en dos de sus lados, provista de escalones de acceso que sirven de comunicación con otras salas (Figura 9). Se abriría hacia el oeste en comunicación con la estancia templada, y al norte conectando con la habitación previa identificada como posible zona de paso. En este ambiente el bañista se despojaba de sus vestimentas y se preparaba para iniciar el circuito del baño que comenzaba con el tepidarium. 


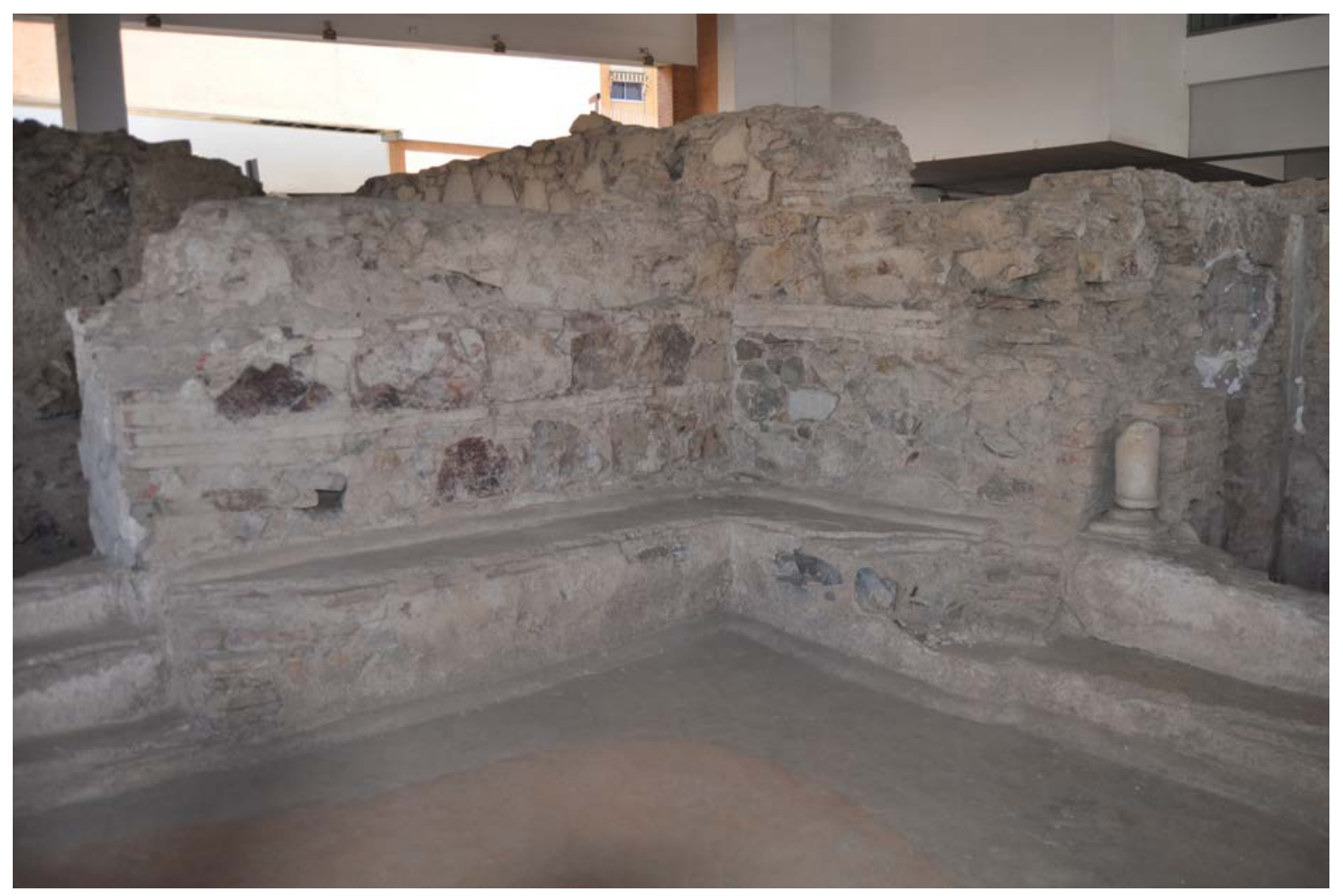

FIG. 9. FOtO dE LOS BANCOS DEL APODYTERIUM de MORERÍA, MÉRIDA. (Fotografía de la autora).

\section{II.1. EL TEPIDARIUM}

Esta sala templada forma un bloque constructivo con la dependencia colindante, el caldarium. La morfología de este tepidarium es rectangular rematando en un ábside. Se calentaba, como es habitual, de forma indirecta gracias a la presencia de un vano (a un nivel más bajo) que lo comunica con la estancia caliente (C). No obstante, no se descarta la existencia de un praefurnium propio abierto a los pies, en el muro de cierre.

El area de la sala sobre la que se levantaban las arquerías de ladrillo, de tegulae invertidas, responde a un modelo inusual para el conjunto emeritense y en líneas generales para los baños de Hispania, aunque cuenta con paralelos como el conjunto termal de la Villa de la Quintana (Palahí y Vivó I996: Io9-II3; Vivó et alii 2006: 6I66, I43, fig. I2).

La habitación estaría provista de un sistema de concameratio (se aprecia la separación existente entre las arcadas de ladrillos y los muros perimetrales), desconociéndose los elementos interiores. Este medio de paso para el calor se ha querido identificar en baños como la Casa del anfiteatro (Reis 2004: 78-79), encontrando también testimonios directos en los baños de la Huerta de Otero (Figura Io), la propia Morería (Mosquera I994: 48-49) o los baños de «Las Abadías» (ss. III-V d.C.) (Méndez 2015: 92, fig. 73). 


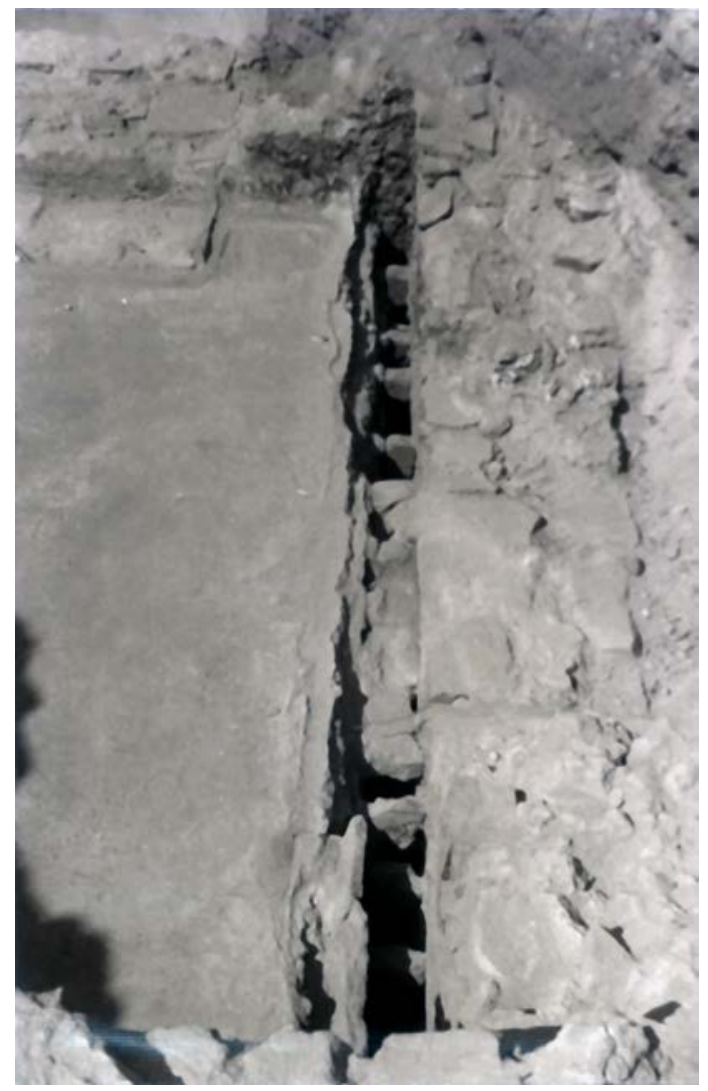

FIG. 10. CONCAMERATIO DE LOS BAÑOS DE LA HUERTA DE OTERO, MÉRIDA.

(Archivo fotográfico Museo Nacional de Arte Romano).
Respecto a su cabecera, espacio igualmente calefactado, estaría ocupada bien por un alveus o labrum (Morillo y Salido 20II: I54-I57), elementos que no se pueden determinar ya que en este punto el paramento de cierre se halla muy afectado por riostras contemporáneas ${ }^{6}$.

En la búsqueda de paralelos del modelo de tepidaria, los ejemplos de baños que se configuran con una planta rectangular rematando su cabecera semicircularmente, son cuantiosos (García-Entero 2005: 793-794). Equipados con alveus semicirculares existen análogos que se reparten por todo el Imperio Romano y, vinculados a los ámbitos domésticos hispanos, García-Entero los agrupa bajo el tipo IV. 4.2 donde engloba, entre otros, los baños urbanos de la casa del Bisbe Caçador (Barcelona), Peri 2 P-3I (Tarragona) o Cercadilla, (García-Entero 2005: 794, figs. 219). Igualmente son numerosos los ejemplos lusitanos analizados por Reis (2004: 89-93, fig. 35; I08III, fig. 47; I37-I38-I39, fig. 73; I49-I5I, fig. 79), siempre ligados al ámbito rural.

Para el en torno urbano de Augusta Emerita, contamos con el modelo de la Casa de los mármoles, con un espacio templado que se desarrolla en una planta rectangular con cabecera semicircular y cámara de calor, cabecera que no acogió ningún recinto para el baño (García-Entero 2005: 539, fig. I60). Por sus características asemeja a nuestro tepidarium, lo que nos induce a pensar que, al igual que éste, la sala templada de Hernán Cortés no hubiera estado provista de alveus.

\section{II.2. EL CALDARIUM}

Continuando con el recorrido habitual del bañista, desde el tepidarium se accedía a través de una puerta a la última sala, el caldarium. En este ambiente, el más caliente de todo el circuito, se tomaba el baño cálido sumergiéndose en piscinas -alveus o alvei- localizadas en esta estancia.

Esta sala caliente, pese a que no hemos podido excavarla en su totalidad, muestra ciertas particularidades que la hacen singular y la distinguen del resto de los complejos termales emeritenses conocidos. Nos estamos refiriendo a la

6. La cabecera, sobre la que apoyaba una gruesa medianera de hormigón de la casa contemporánea, aparece muy deteriorada, lo que sumado a la parcialidad de la excavación en este punto del solar motivó que no se ha podido hallar, de existir, el canal de desagüe de este alveus. 
presencia de los dos alvei que, en este caso, no están directamente calefactados por un praefurnium propio, sino que obtenían el calor del mismo horno que alimentaba la sala y el tepidarium.

Estos alvei, destinados a acoger agua caliente, son dos pequeñas piscinas que al interior presentan prácticamente el mismo diámetro, pero que al exterior se configuran como módulos uno mayor que el otro. Las piscinas, no excesivamente profundas, funcionarían a modo de asientos y se ingresaría a ellas mediante escaleras. La presencia de agua en su interior queda confirmada por la existencia de dos orificios de desagüe que evacuaban al exterior, a través de sendas canalizaciones. El encañado responde a una superficie de mortero de cal cóncava que conducía el agua a través de un canal de ladrillos. Estos canales corren en paralelo probablemente hasta desaguar en la red de cloacas de la ciudad, estando protegidos por una solera de opus signinum, el nivel de pavimento de esta zona de servicio.

A la hora de buscar similitudes para esta morfología de caldaria, estudios consultados ponen de relieve la escasez de paralelos debido a lo inusual de las cabeceras doblemente absidadas en las estancias calientes. Mayoritariamente se registran ejemplos que, para los casos conocidos, se refieren al modelo de alveus único (García-Entero 2005: 796-797, fig. 226 y 228).

No obstante, en los escasos baños en los que se constata la presencia de dos o más alvei, éstos se disponen afrontados o bien perpendiculares, una circunstancia que García-Entero define como infrecuente en los edificios urbanos (2005: 797).

Es la aparición de dos ábsides sobre el mismo muro, tal y como sucede en nuestro caldarium, un elemento singular y así lo confirma Bouet que los cataloga bajo la fórmula de doble ábside yuxtapuesto, clasificado dentro del tipo $9 \mathrm{c}$, describiéndolos como «deux solia juxtaposés sur la même paroi» (Bouet 2003a: 86-87, pl. 72). Para estos ejemplos, la parte calefactada corresponde únicamente a la sala central y no a las piscinas ${ }^{7}$.

Si bien nuestro caldarium se englobaría dentro de esta tipología, sin embargo presenta la singularidad de que, en este caso, no sólo la sala principal estaría calefactada sino también ambas piscinas. Así parecen confirmarlo los huecos centrales existentes en el frente de ambos alveus ${ }^{8}$, pasos de calor semejantes a los hallados en el tepidarium, lo que permitirían mantener el agua acumulada a una temperatura agradable.

Centrándonos en la búsqueda de paralelos, para los baños de Augusta Emerita tenemos mayoritariamente registrados los modelos de un solo alveus semicircular en su sala caliente, como los hallados en los baños del Centro Cultural Alcazaba (Barrientos I997: 272, fig. 4) o en la Casa del mitreo (García I969: 3-7; Mora I981: 74, fig. 242; Barrientos I997: 264, fig. 2). En la Casa de los mármoles, del Área

7. Bouet establece un listado de caldaria provistos con estos alvei yuxtapuestos, donde se puede observar una preferencia por la planta rectangular. Cita como modelos los de Saint-Bertrand-de-Commingues, Sorde-l'-Abbaye, con una datación que lo sitúa en el s. IV d.C., o Frejús, con una cronología algo más temprana (a. 70-80). Como único ejemplo de baños semicirculares yuxtapuestos, menciona las termas de Carrawburgh (GB), que fecha, de manera poco concluyente, en el s. IV d.C.

8. No se han conservado los restos del hypocaustum de los alvei. La reutilización de ambas piscinas como silosbasureros en época emiral, implicó el rebaje y arrasamiento de los mismos. 


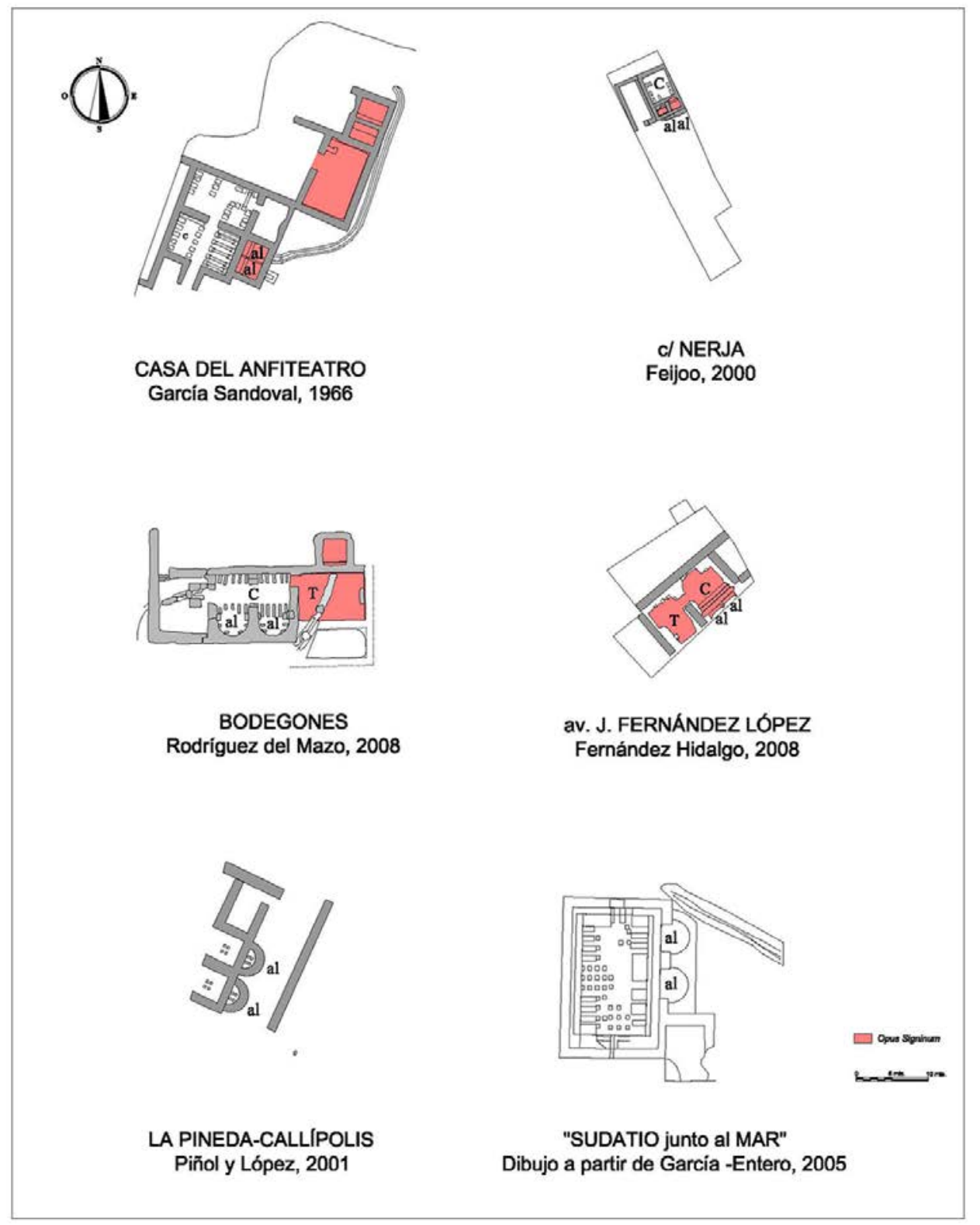

FIG. 11. PLANTAS DE BAÑOS DOMÉSTICOS CON CALDARIA DE CABECERAS DOBLES. (Planimetría de autor).

Arqueológica de Morería, nos encontramos con un ejemplo de caldarium que presenta dos alvei semicirculares uno afrontado al otro (Mosquera 1994: 42-49; Alba I997: 285-315).

La duplicidad yuxtapuesta, es decir dos alvei sobre una misma pared, se asocia con piscinas rectangulares para las que conocemos, igualmente, varios ejemplos emeritenses (Figura II). El primero de ellos se sitúa en los baños excavados en la Casa del anfiteatro, datados a mediados del s. Ill d.C. (Barrientos 1997: 263-264, fig. 2; García-Entero 2005: 549-552, fig. I62, lám. XXXV y XXXVI), provistos de sendas piscinas a las que accedía el bañista bajando dos peldaños; los baños de la Casa basílica que se fechan entre mediados del s. Il e inicios del s. IV d.C.; los dos 
alvei identificados en los baños de la c/ F. Valverde Lillo, $n .^{\circ}$, que no se determina si pertenecían a un tepidarium o frigidarium (Sánchez 2002: 200-201), o los alvei rectangulares asociados al caldarium de los baños localizados en la c/ Nerja datados en época visigoda (ss. VI-VII d.C.) (Feijoo 200o: 333-357, lám. 2).

Recientemente se han excavado otros dos complejos balneares. El primero situado en una domus periurbana en la zona de los «Bodegones», encuadrado en el bajoimperio, que presenta dos ábsides semicirculares sobre un único muro formando parte del espacio caliente (caldarium), pero que en su cámara subterránea configuran dos salas simétricas, provistas de alveus, lo que establece ciertas diferencias con el caldarium que presentamos (Barrientos 20II: 340, fig. 2, nota 22)9.

Un segundo baño que mencionar, es aquél documentado con motivo de una excavación en un solar próximo a la muralla romana, en una de las areae cercanas al río Ana, en la actual av. José Fdez. López, $\mathrm{n} .^{\mathrm{o}} \mathrm{I2}^{\mathrm{Io}}$. En este punto se ha excavado un complejo termal que guarda una gran similitud con el analizado por nosotros en estas páginas.

La intervención arqueológica, dirigida por F. Sánchez, puso al descubierto un balneum, con una secuencia de salas lineal-retrógrada, de la que se pudieron documentar tres estancias: el propnigeum, un tepidarium y un caldarium que, al igual que nuestro baño, comparten el mismo nivel de suelo y un acceso en la parte central entre ambas estancias.

No obstante, lo destacado de este conjunto es el caldarium, provisto de dos alvei en su cabecera, de los que no se puede determinar su morfología rectangular o semicircular (no han sido excavados íntegramente), que están separados por un tabique de ladrillo y a los que se accedía por una escalera común. Esta construcción la fecha su excavador en torno a los s. II-III d.C., estando amortizada ya en el s. V d.C.

Fuera del ámbito emeritenses, encontramos un paralelo para esta cabecera doblemente absidada en la tarraconense Villa de Els Munts, concretamente en sus instalaciones denominadas «Sudatio junto al mar», que se ubican en la propia playa y se asocian a una villa. De esta edificación, de pequeñas dimensiones, han sido excavadas únicamente dos estancias. La mayor es una amplia sala rectangular que cierra, a oriente, en un muro que alberga dos absidiolos en los que pudieron instalarse bañeras. Esta sala ha sido interpretada como un caldarium y su datación no ha podido ser concretada, fechándose, grosso modo, entre los ss. I-VI d.C. (GarcíaEntero 200I: 223; ibid 2005-2006: 8I-82, fig. 62, Lám. XIII).

Otro ejemplo similar, aunque con la salvedad de corresponder a dos salas (caldaria), lo hallamos en los baños de la villa de La Pineda-Callípolis (Vilaseca). De cronología tardía, mitad del s. IV- principios del s. V d.C., en este periodo se documenta una última reforma de un balneum altoimperial que consiste, básicamente, en

9. Agradezco a Raquel Rodríguez del Mazo, directora de la intervención arqueológica, la documentación que me ha aportado.

10. Agradecer a Fernando Sánchez Hidalgo la información facilitada y que queda recogida en el artículo «El balneum de la casa de presidencia (c/ José Fernández López, Mérida)», publicación que se engloba dentro una monografía sobre la arquitectura termal en Augusta Emerita, en fase de elaboración por parte del Consorcio de la Ciudad Monumental de Mérida. 
compartimentar y modificar las estancias del complejo preexistente, especialmente las salas calientes y, con mayor énfasis, el caldarium, que se configura como una sala doble provista de sendos alvei en su cabecera (Piñol y López 200r: 83-85, fig. 4; Díaz y Macias 2007: I40, fig. 13).

\section{CONCLUSIONES}

A modo de síntesis, gracias a la intervención arqueológica realizada en la c/ Hernán Cortés n. ${ }^{\circ} 44$ de Mérida, podemos añadir un nuevo balneum de carácter privado a la amplia lista de complejos termales de Augusta Emerita excavados en los últimos años en la ciudad. Pese a que su cronología no ha podido ser especificada, ante la ausencia de materiales arqueológicos, planteamos una datación tardía para este complejo, en torno al s. IV d.C., debido a su vinculación con estructuras cercanas localizadas en este solar y, por su proximidad a una domus excavada en un solar anexo (Figura I2).

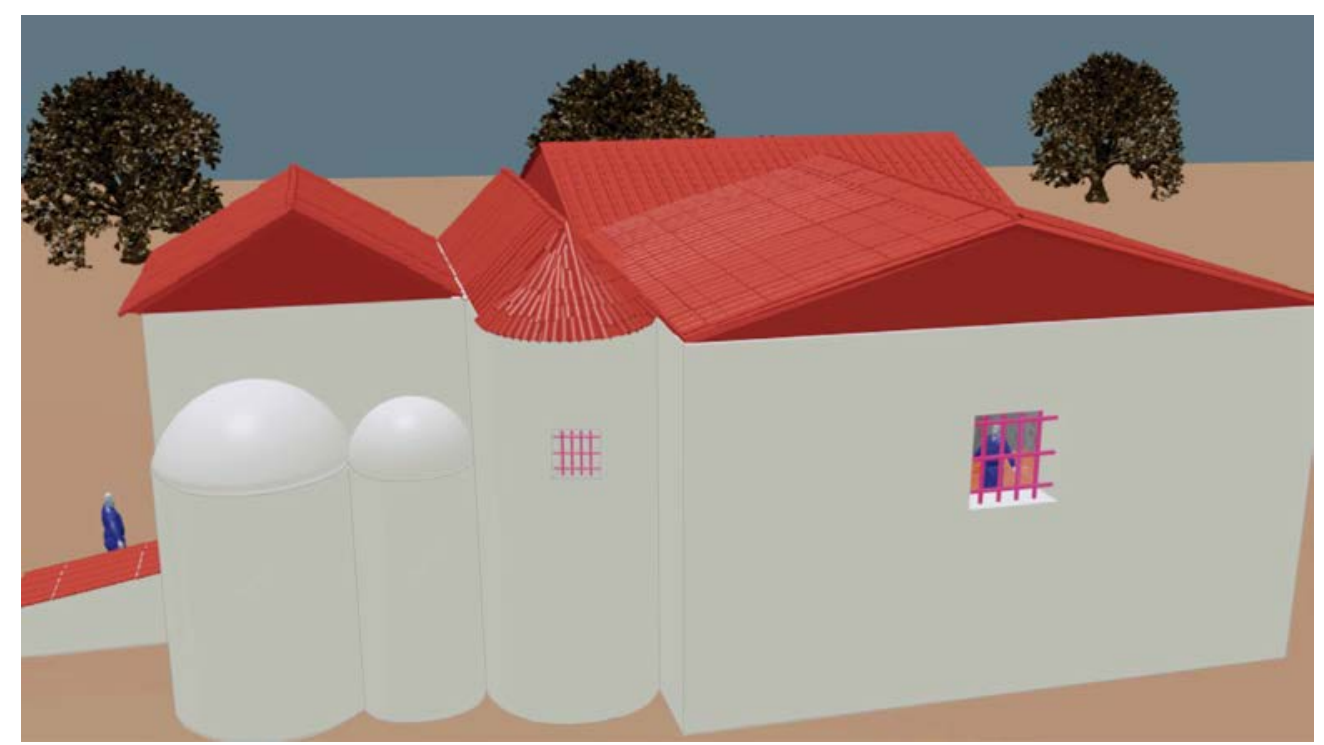

FIG. 12. RECONSTRUCCIÓN HIPOTÉtiCA de LOS BAÑos de LA C/ hERNÁN CORTÉS. (José Antonio Jiménez, CCMM).

Este baño se incorporaría a la arquitectura de una domus de amplias dimensiones pese a que, debido a la parcialidad de la excavación, no hemos podido vincularla directamente.

En cambio, sí conecta con otras estructuras localizadas en el solar cuyas trazas induce a pensar en un corredor o espacio de separación, un pasillo que conectaría los baños con otras dependencias de la misma casa.

También podemos afirmar que este conjunto balnear se engloba dentro de un proyecto más amplio de reforma y ampliación de la vivienda, como evidencia la amortización de estancias previas para la construcción de este balneum.

Esta modificación integral de la domus con la implantación de unos baños de uso privado, está en consonancia con el desarrollo urbanístico y arquitectónico que 
tuvo Augusta Emerita durante el s. IV d.C. incentivado, indudablemente, por ser la sede del Vicarius Hispaniarum. Gracias a la arqueología contamos con numerosos testimonios que avalan este proceso, tanto dentro del recinto amurallado como extra-pomerium, documentándose viviendas donde, durante esta etapa, se las dota de salas absidadas, ricos programas decorativos y, sobre todo, baños privados.

Para finalizar el estudio de este balneum, ya hemos reiterado su pertenencia a una domus de cronología bajoimperial. Ante la falta de concreción del recorrido de la muralla en este sector, y a pesar de establecer su probable ubicación extramuros, sin embargo resulta problemático situar esta vivienda dentro o fuera de la cerca romana. No obstante, la excavación de este espacio emeritense nos aporta datos sustanciales que sumar al conocimiento del urbanismo de esta parte suroriental de Augusta Emerita, el área limítrofe al recinto amurallado o su diacronía ${ }^{\text {II }}$.

\section{MATERIALES CONSTRUCTIVOS}

Las últimas y continuadas excavaciones arqueológicas realizadas por el Consorcio de la Ciudad Monumental de Mérida, nos han permitido ampliar el conocimiento de los complejos termales de Augusta Emerita. También, cómo no, de los materiales constructivos empleados en sus hypocausta. De los documentados en este solar, vamos a enumerar los vinculados a la construcción del balneum.

\section{Bessalis}

Estos elementos hallados in situ conforman la base de los arcos de sustentación de la suspensura, concretamente del tepidarium, único ámbito en el que se han conservado.

En el caso de los bessalis de los arcos, las dimensiones del primer apoyo son de I9 X I9 x 4 cm, con una ligera variación en uno de ellos de I8' 5 x 4 cm de grosor, con una torta de cal de I' $5 \mathrm{~cm}$ de media. El siguiente arranque utiliza módulos de 20 x $20 \mathrm{~cm}$ y I8' 5 x I7' 5 x $4 \mathrm{~cm}$.

Los módulos en la zona correspondiente a la cabecera absidada varían entre los I9'5 x I9'3 X 4 cm / I9 x I8' 5 x 3 cm / I9 x I8'5 x 3'5 cm y I9 x I8'5 x 4 cm. Este ladrillo responde habitualmente a un modelo cuadrado de 19 ' $7 \mathrm{~cm}$, que Vitrubio relaciona con las pilae de sostenimiento de las arcadas de la suspensurae. En las termas hispanas sus medidas oscilan entre I8 y $24 \mathrm{~cm}$ (Fernández et alii, I999: 300).

Para los baños emeritenses, los bessalis, generalmente irregulares, se registran en el balneum de la c/ Sagasta, de 20 x 20 cm (Chamizo 2015); en el área arqueológica de Morería (finales s. III-IV d.C.), ligeramente mayores y empleados en los arcos del caldarium; en las termas de Resti, tanto en las salas calientes como templadas, con unos módulos que varían entre los i9 y 2I cm; en los baños de la av. Fernández López,

11. A lo largo de los últimos años, se han realizado numerosas intervenciones arqueológicas fruto de la labor preventiva llevada a cabo por el Consorcio de la Ciudad Monumental de Mérida, intervenciones que han sido publicadas en la revista Memoria o bien permanecen aún inéditas y pendientes de su publicación, lo que nos ofrece un panorama ampliado de los baños emeritenses. 
con medidas similares (Sánchez, e.p.); en la c/ Carderos n. ${ }^{\circ} 3$ donde, amortizando un área funeraria a mediados del s. III d.C., se construye un balneum que continuará en uso hasta finales del s. IV d.C., con ladrillos de $20 \times 20 \times 4 \mathrm{~cm}$ sobre solera de $40 \times 30 \times 4 \mathrm{~cm}$ (Vargas y Plasencia 2015), o en las salas calientes y templadas del complejo termal situado en la zona de Las Abadías datado en época bajoimperial, de 20 ' 5 × 20 ' 5 × 3' $5 \mathrm{~cm}$ y 20 x 20 x $4 \mathrm{~cm}$ sustentados sobre una base de arco de $40 \mathrm{x}$ 26 × 4 cm/4I'5 x 27 x 4 cm (Méndez 20I5).

Todos estos baños, al igual que el que presentamos de la c/ Hernán Cortés, sostienen la suspensura sobre arcos latericios, esquema que se repite en la mayoría de las estructuras balneares documentadas en la Lusitania. En estos casos, y de forma generalizada, los arcos arrancan desde el nivel de suelo de la cámara inferior asentados sobre soleras de losas de barro (Reis 2004: 55-56).

\section{Bessalis en cuña (cuneati).}

Encontramos piezas de forma trapezoidal de $26 \times 25 \times 4 \mathrm{~cm}$, con recortes y un lado más grueso que el otro, entre los rellenos localizados en el caldarium y en el tepidarium, en el espacio intermedio entre las pilae de apoyo y los muros. En definitiva, removidos de su lugar original.

Estos ladrillos se identifican claramente con la formación de arquerías, en este caso vinculada a los elementos sustentantes del pavimento, relacionados con el sistema de calefacción (Brodribb I987: 43-47) (Figura 13).

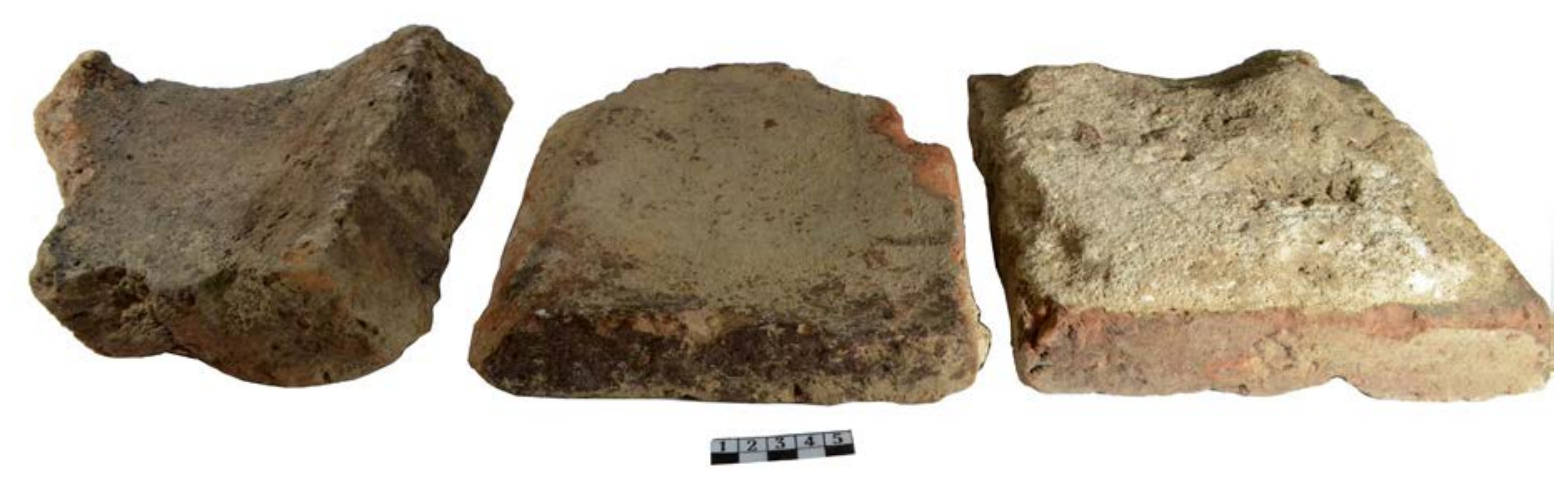

FIG. 13. LAdRILlOS hallados en los niveles de LAS TERMAS. (Archivo fotográfico Consorcio Ciudad Monumental de Mérida).

\section{Pedalis}

Estos materiales se han hallado en los paramentos de separación de la sala del caldarium y los alvei. Son igualmente utilizados en la construcción del muro oriental del tepidarium. Hay que reseñar, asociados a los niveles de destrucción, la presencia de ladrillos pedalis $-29 \mathrm{~cm}$ long. x 4-6 cm grosor medio- que formarían parte de los pilares de separación del alveus.

Trapezoidales de lengüietas (Figura I4)

Otro tipo de ladrillo registrado es el documentado en la construcción del muro de separación entre el apodyterium y el tepidarium. Son piezas de barro cocido que se 


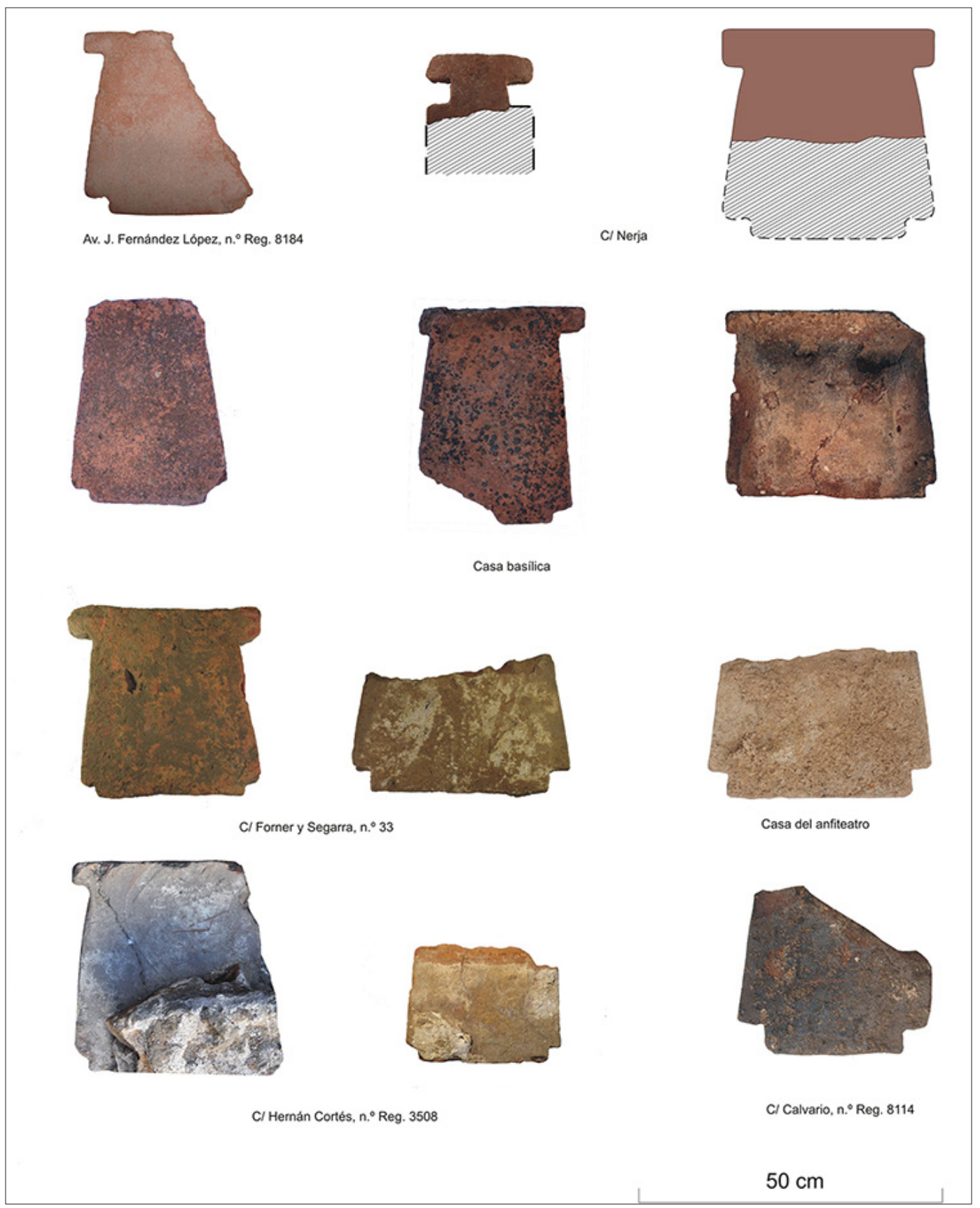

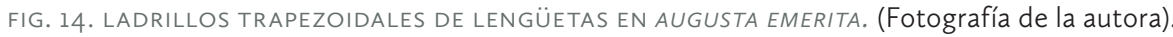

asimilan a las formas trapezoidales de lengüetas tipo 3b (c) de Bouet (Bouet 1999: 94. fig. 56), o el tipo 7 B de Dias (Dias I999: 285). Ladrillos similares aparecen también en los niveles de amortización del complejo balnear, probablemente vinculados a la destrucción de los muros en alzado.

La documentación de esta tipología de ladrillos, muy extensa, básicamente nos remite a su uso dentro de los complejos de baños ya sean públicos o privados. En los casos en los que se han podido documentar in situ, su utilidad era diversa ya 
que bien se empleaban como elementos en la construcción de las bóvedas, en las paredes, constituyendo cámaras de paso de calor, o bien como piezas reutilizadas en muros -como nuestro caso- o en las pilae de los hypocausta (Fincker I986: I43I50; Roldán 2008: 754).

En Mérida, ladrillos con escotaduras similares los encontramos en la Casa basílica, usados como elementos constructivos de los arcos de apoyo de la suspensura, catalogados en los grupos $3^{\circ}$ b (a y d) y 3 b (h) de Bouet (I999: 93-95, fig. 56 y fig. 57), o en la c/ Nerja entre los materiales del relleno del caldarium de los grupos $3^{\circ} \mathrm{b}$ (a) y 5 a (d). También en el complejo de baños de la av. Fernández López, n. ${ }^{\circ}$ I2, usados con probabilidad en las cámaras parietales; en la Casa del anfiteatro, hasta la fecha sin ubicación precisa; en la excavación de la c/ Calvario, n. ${ }^{\circ} 25$ entre los materiales de relleno, todos del tipo 3b (Bouet I999: 93-95, fig. 56, a) (Rodríguez 2006); en las termas de las Abadías, donde entre los materiales de amortización se recogen ladrillos similares a los que se asocian clavos en T (grupo 3a) (Méndez 2015), o en la reciente excavación en la c/ Forner y Segarra donde se han documentado varios ladrillos del tipo 3b (Bouet 1999: 93-95, fig. 56, a), asociados a un área industrial y un espacio doméstico (Bejarano 2015 dpto. doc. 3513).

\section{Ladrillos rectangulares (Figura 15 )}

En los niveles de destrucción se han documentado fragmentos de laterculi (Roldán 2008: 760), ladrillos rectangulares de sección cuadrada o rectangular, con unas medidas de I3'9 (incompleto) x 4'9/5 × $6 \mathrm{~cm}$.

Para Augusta Emerita, piezas similares se han localizado en la Casa del anfiteatro

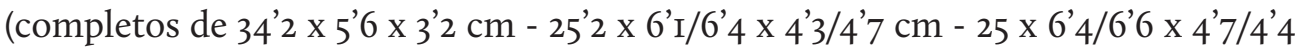

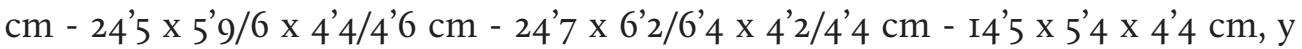
fragmentados de I4'7 x 6'2 x 4'5 cm - I4'7 x 6005 x 4'5 cm - 9'7 x 4'95 x 4'25 cm - Io'7 x 6'85 x 4'2 cm - I0'5 x 4'35 x 4'35 cm - I5'5 x 4'9 x 4'I cm -- Io' 4 x 6 x 4'I cm I5'6 x

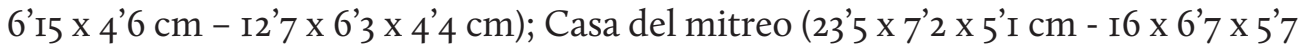
$\mathrm{cm})$; en la Casa basílica $(36 \times 8 \times 8 \mathrm{~cm})$ o en el complejo excavado en la c/ Pedro M. ${ }^{\mathrm{a}}$ Plano, n. $^{\circ} \mathrm{I}^{\mathrm{I} 2}$. Con dimensiones menores ( $18 \times 7^{\prime} 5$ x $5^{\prime} 2 \mathrm{~cm}$ ) los tenemos registrados en los baños de «las Abadías», asociados a las concameratio de las estancias calientes (Méndez 2015).

Esta tipología de ladrillos era empleada, indistintamente, en la construcción de las cavidades interiores de los muros en las salas calientes o bien, en ciertos casos, en los pavimentos (Biers 1988: 209, figs. 200 y 264).

\section{Tegulae}

Las tégulas debieron conformar la cobertura de este balneum y de la domus (Brodribb I987: 2I-22). No obstante, para este caso concreto también fueron empleadas en la pavimentación del Tepidarium y el Caldarium, teniendo en cuenta las conservadas in situ, estando colocadas de forma invertida. Las medidas documentadas son de 52 x 4I cm / 54'5 x $42 \mathrm{~cm} / 5 \mathrm{I}-52 \times 30 \mathrm{~cm} / 53 \times 39 \mathrm{~cm} / 55$ X

12. Bejarano 2008, dep. doc., n. ${ }^{\circ}$ reg, 3505 . 


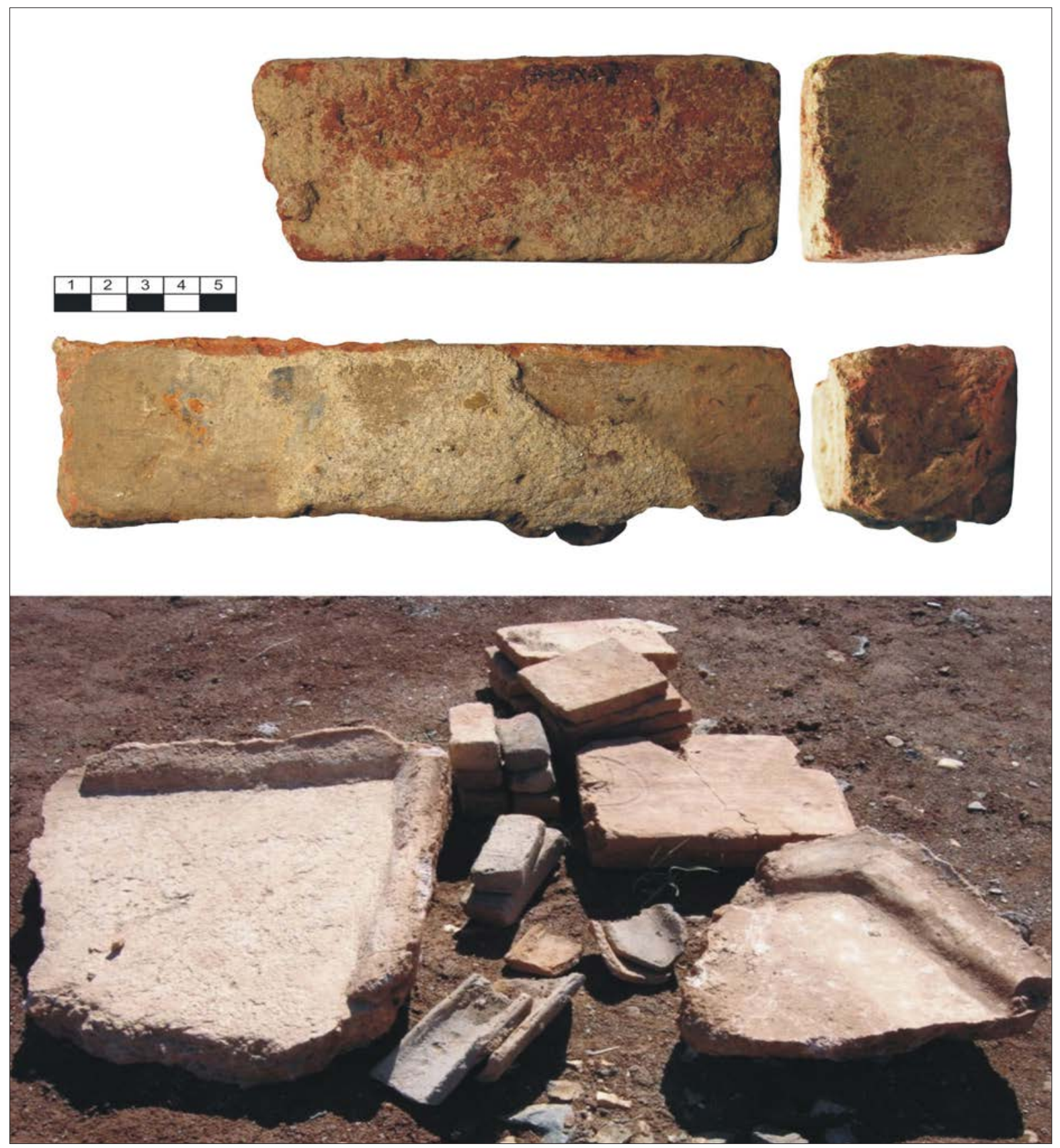

FIG. 15. LADRILLOS RECTANGULARES (C/ HERNÁN CORTES, N. ${ }^{\circ}$ REG. 3508) Y MATERIALES CONSTRUCTIVOS DE LAS TERMAS DE «LAS ABADÍAS». (Fotografía de la autora / Guadalupe Méndez Grande)

$44 \mathrm{~cm}$, mientras que el grosor medio de todas ellas es de 3’5-4 cm. Además de las conservadas in situ, en los contextos de amortización hemos podido recoger un fragmento que nos muestra una tegula con pestaña que se inclina hacia el exterior y remate redondeado.

En el citado solar cercano al nuestro situado en la c/ Hernán Cortés, n. ${ }^{\circ}$ 37, apareció en una de las dependencias de la casa romana un cuantioso y ordenado 


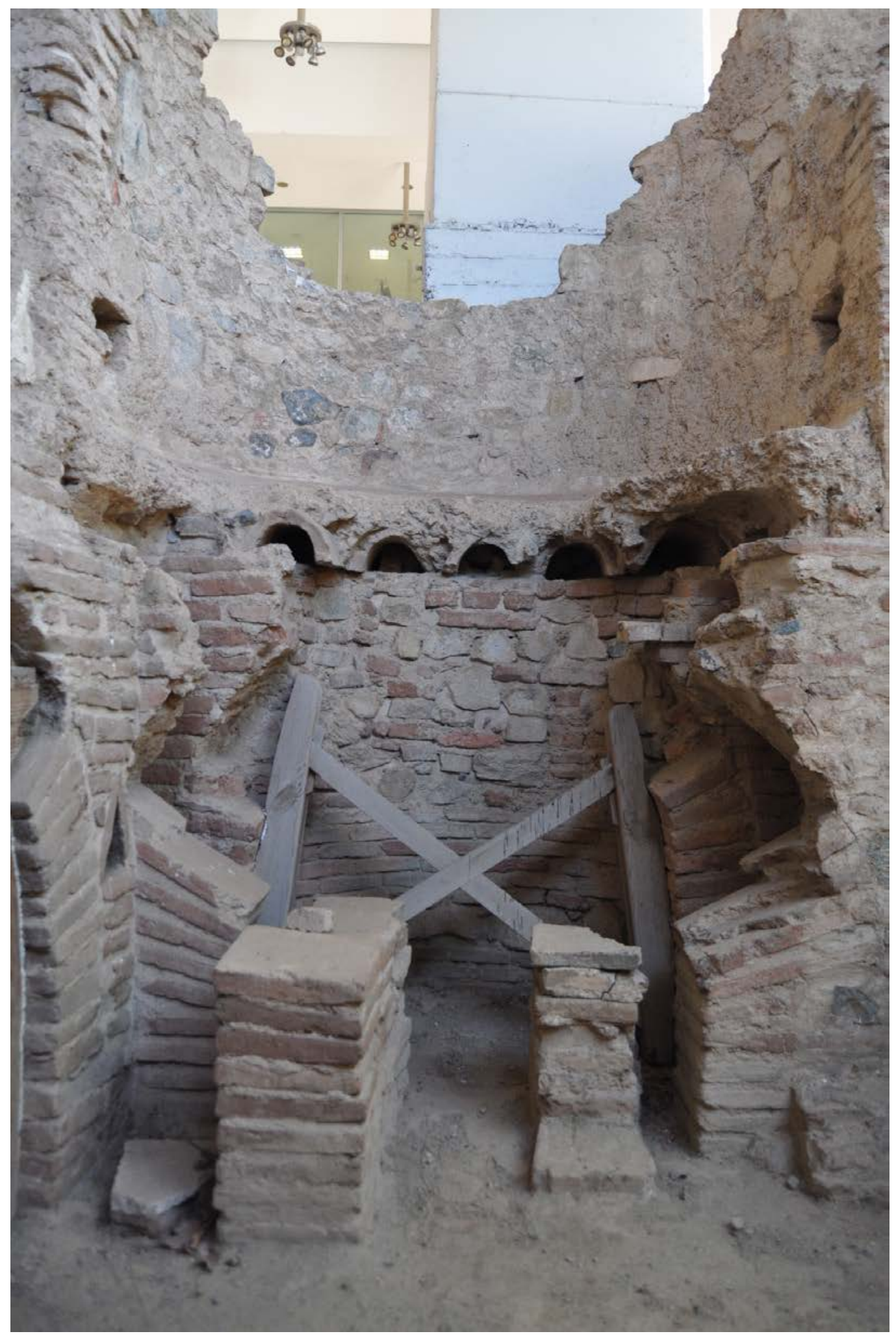

FIG. 16. SISTEMA DE SUSPENSURA Y CONSTRUCCIÓN DE LOS SUELOS DEL TEPIDARIUM DE MORERÍA, MÉRIDA. (Fotografía de la autora). 
apilamiento de tégulas completas datadas en el s. IV d.C. (Bejarano 2007: 240-243, figs. II y I2). Pues bien, estas tegulae presentas las mismas dimensiones y escotaduras que las utilizadas en el pavimento de nuestro tepidarium. Por ello, estimamos que la procedencia de ambos contextos podría ser la misma.

Respecto al conjunto de baños emeritenses, el sistema de pavimentación empleado en este balneum es singular ya que, en la mayoría de los complejos conocidos, como suelos de las cámaras utilizan bien las losas de barro cocido -mayoritariamente el lydion con diversas variantes-, los pavimentos de opus signinum o, simplemente, la roca natural enrasada.

Îmbrices

Para concluir la enumeración de los materiales constructivos empleados en este nuevo balneum emeritense, se han localizado también restos de ímbrices que presentan la cara interior calcinada y la exterior con restos de argamasa.

El empleo de estas tejas en los baños de Augusta Emerita ha sido constatado en las termas del Área Arqueológica de Morería, donde se nos muestra uno de sus diferentes usos, en este caso como apoyo de la solera del alveus del tepidarium, o en los niveles de destrucción de los baños del área de «Los Bodegones» formando parte del sistema de suspensura del caldarium (Figura I6).

Para el resto de la provincia lusitana, Reis concluye en su estudio que los pavimentos de las áreas calientes apoyaban, generalmente, sobre un nivel de ímbrices que mostraban la separación entre los arcos de las suspensurae. Ejemplos de su utilización los verificamos, dentro de ambientes urbanos públicos, en las termas de la muralla de Conímbriga (Reis 2004: 65); las termas del este de Miróbriga en su tepidarium (Reis 2004: 75) y las termas del oeste en su caldarium (Reis 2004: 77). Ya en ámbitos privados, en la Casa de Cantaber cuyo caldarium, asociado a la última reforma, construye su pavimento con imbrices superpuestos por una gruesa capa de opus signinum (Correia y Reis 2000: 277).

En contextos urbanos, pero fuera de la Lusitania, contamos con el ejemplo de las termas de Gijón, que utiliza este material en las suspensurae. Concretamente la sudatio, asociada a una segunda fase constructiva, emplea ímbrices ( 48 x 2I x IO $\mathrm{cm})$ que apoyan sobre una lechada de mortero de cal mezclada con ladrillo, teja y piedra, rellenando el tímpano y sobre ésta una pavimentación de opus signinum (Fernández y Zarzalejos I996: II6; Fernández et alii 1997: 24-28). 


\section{BIBLIOGRAFÍA}

Alba Calzado, M. I997: «Ocupación diacrónica del área arqueológica de Morería (Mérida)», Mérida, excav. arqueol., I994-I995, I, 285-315.

- 2004: «Arquitectura doméstica», en Las capitales provinciales de Hispania. Mérida, Colonia Augusta Emerita, «L'Erma» di Bretschneider, 2, Roma, 67- 83.

Álvarez Martínez, J. M. ${ }^{a}$ I990: Mosaicos romanos de Mérida. Nuevos hallazgos. Monografías Emeritenses, 4, Madrid-Mérida.

Barrientos Vera, T. I997: «Baños romanos en Mérida. Estudio preliminar», Mérida, excav. arqueol., I994-I995, I, 265-266.

- 2000: «Intervención arqueológica en el solar de la c/ Parejos, $n^{0} 32$. Un ejemplo de reutilización de estructuras desde época altoimperial hasta la tardoantigüedad», Mérida, excav. arqueol., I998, 4, 221-275.

- 20II: «Arquitectura termal en Mérida. Un siglo de hallazgos», en Álvarez, J. M. a y Mateos P. (eds), Actas del Congreso Internacional «I9ıo-20Io: el Yacimiento Emeritense», Mérida, 2OIO, 327-342.

Bejarano Osorio, A . 2007: «Una domus extramuros en los límites de la ciudad: nuevos aspectos de la urbanística y el trazado de la muralla de Augusta Emerita en la zona oriental. Intervención arqueológica realizada en la C/ Hernán Cortés, $n^{\circ}$ 37», Mérida, excav. arqueol., 2004, 10, 233-256.

BIERs, W. R. I988: Miróbriga. Investigations at an Iron Age and Roman Site in Southern Portugal by the University of Missouri-Columbia, I98I-I986, BAR Internacional Series, 45I, Oxford.

Blanco Freijeiro, A. I976: «Los mosaicos romanos de Mérida», Actas del Simposio «Bimilenario de Mérida», Mérida I975, I88-189.

- I978: «Mosaicos romanos de Mérida», Corpus de Mosaicos Romanos de España, T. I. Madrid.

Bouet, A. I999: Les materiaux de construction en terre cuite dans les thermes de la Gaule Narbonnaise. Ausonius Publications, I, Bourdeaux.

- 2003: Thermae Gallicae: les thermes de Barzan (Charente-Maritime) et les thermes des Provinces Gauloises, Aquitania Supplèment, II, Mémoires, Bordeaux.

- 2003: Les thermes privés et publics en Gaule Narbonnaise. Collection de l'École Française de Rome, 320, Roma.

Brodribb, G., I987: Roman Brick and Tile. Great Britain.

CorreiA, V. H. y Reıs, M. ${ }^{a}$ P. 200o: «As termas de Conimbriga: tipologias arquitectónicas e integração urbana», en Fernández Ochoa, C. y García Entero, V. (ed.), Termas romanas en el occidente del Imperio, II Coloquio Internacional de Arqueología, Gijón, 27I-280.

Chamizo de Castro, J. J. 20I5: «Ocupación doméstica, un ejemplo de diacronía en Mérida. Intervención arqueológica realizada en la calle Sagasta $n^{\circ} 25$ (Mérida)». Mérida, excav. arqueol., 2005, II, 247-26I.

DiAs, L. I999: «Arquitectura com tijolo em Tongobriga: seudo dos materiais das Termas e dos aparehos dos muros», en Bendala, M., Rico, Ch. y Roldán, L. (eds.), El ladrillo y sus derivados en época romana, Monografías de Arquitectura Romana, 4, Madrid, 277-29o.

Díaz García, M. y Macias Solé, J. M. a 2007: «La villla romana de la Pineda/Cal-lípolis (Vilaseca, Tarragonès)», El territori de Tarraco: villes romanes del Camp de Tarragona. Actes del Seminari organitzat pel Museu Nacional Arqueològic de Tarragona, la Societat Catalana d’Estudis Clàssics i l'Institut Català d'Arqueologia Clàssica, amb la colllaboració de la 
Facultat de Lletres de la Universitat Rovira i Virgili, Tarragona, I4, I5 i 16 de febrer de 2006. Temes d'història i d'arqueologia tarragonines, I33-15I.

FeIjoo Martínez, S. 2000: «Intervención arqueológica en la zanja para la canalización de aguas de la c/ Nerja. Unas termas de época visigoda extramuros de la ciudad». Mérida, excav. arqueol., I998, 4, 333-357.

Fernández OchoA, C., ZARZAlejos, M. ${ }^{a}$ del M. 1996: «Técnicas constructivas en las termas romanas de Campo Valdés (Gijón): el material latericio», A.Esp.A, 69, I09-II8.

Fernández Ochoa, C., García Díaz, P., Guiral Pelegrín, C. y Mostalac, A. i997: Las termas romanas de Campo Valdés. Fundación Municipal de Cultura, Universidad Popular del Ayuntamiento de Gijón, Gijón.

Fernández Ochoa, C., Morillo, A., Zarzalejos, M. ${ }^{a}$ del M. I999: «Material latericio en las termas romanas de Hispania», en Bendala, M., Rico, Ch. y Roldán, L. (eds.), El ladrillo y sus derivados en época romana. Monografías de Arquitectura Romana, 4, Madrid, 29I-306.

FinCKER, M. 1986: «Les briques claveaux : un matériau de construction spécifique des thermes romains», Revue Aquitania, 4 , I43-I50

García-Entero, V. 200I: Los balnea de las villae hispanorromanas: provincia Tarraconense, Monografías de Arquitectura Romana, 5. Madrid.

- 2005: Los Balnea domésticos -ámbito rural y urbano- en la Hispania romana, Anejos de A.Esp.A, XXXVII. Madrid.

- 2008: «El ocio en el ámbito doméstico de la arquitectura hispanorromana: las termas», La arquitectura doméstica romana en el ámbito urbano y rural, An. Murcia, 23, 249-268.

García SANDoval, E. 1969: «El mosaico cosmogónico de Mérida», XI Congreso Arqueológico Nacional, Zaragoza I970, 3-7.

Malalana Ureña, A., Morín de Pablos, J. y Barroso Cabrera, R. 2oiz: «Acerca de la funcionalidad de los denominados «silos-basureros»: una propuesta metodológica para el estudio de la agricultura andalusí en época califal y taifa», Archeologia Medievale, XL, $337-352$

Martín, A., Miró, N., Revilla, E. 200o: «El complejo termal privado de la domus de la calle Bisbe Caçador de Barcelona», en Fernández Ochoa, C. y García Entero, V. (eds), Coloquio Internacional Termas romanas en el Occidente del Imperio, Gijón, 2000, 283-287.

Méndez Grande, G. 2004: «Restos de una domus con pavimento musivo y su posterior evolución. Intervención arqueológica realizada en el solar $n^{\circ} 83$ de la calle Suárez Somonte», Mérida, excav. arqueol., 2001, 7, 257-267.

- 2015: «Hallazgo de un cuarto Acueducto en Augusta Emerita, junto a la Vía de la Plata. Intervención arqueológica efectuada en el Residencial Las Abadías (Mérida)», Mérida, excav. arqueol., 2005, II, I7-I00.

Morillo, A. y SAlido Domínguez J. 2oII: «Labra de época romana en Hispania», A.Esp.A, 84, I53-178.

Mosquera MülLER, J. L. I994: «Excavaciones en el barrio emeritense de Morería», Revista de Arqueología, 158, 42-49.

Nielsen, I. 1993: Thermae et Balnea . The Architecture and Cultural History of Roman Public Baths. Aarhus University Press, Aarhus.

Palahí i Grimm, Ll. y Vivó i Codina, D. I996: «L' evolució dels conjunts termals en el nordest de Catalunya: els casos de les vil.les dels Ametilers (Tossa de Mar) i la Quintana (Cervià de Ter)», Cypsela XI, I05-II5.

PERICH i RocA, A. 20I4: Arquitectura residencial urbana dèpoca tardoantiga a Hispania (segles IV - VIII d. C.), Institut Català d'Arqueologia Clàssica, Universitat Rovira i Virgili, Tarragona. 
Piñol MASGORET, LL. y LÓPEZ VILAR, J. 20oI: «Complejos termales en las villae tardorromanas del Camp de Tarragona (Ager Torroconensis)», Arqueología y Territorio Medieval, 8, Jaén, $83-85$.

ReIs, M. ${ }^{a}$ P. 2004: Las termas y balnea romanos de Lusitania. Studia Lusitana, I, Madrid.

ROLDÁN, L. 2008: «El material constructivo latericio en Hispania: Estado de la cuestión», en Bernal Casasola, D. y Ribera i Lacomba, A. (eds), Cerámicas Hispanorromanas. Un Estado de la Cuestión, Cádiz, 749-773.

SÁnchez Barrero, P. D. 2007: «Trabajo desarrollado por el Equipo de Seguimiento de Obras durante el año 2004», Mérida, excav. arqueol., 2004, I0, 409-429.

SÁNCHEZ SÁNCHEZ, G. y NodAR BECERRA, R. I997: «Reflexiones sobre las casas suburbanas en Augusta Emerita», Mérida, excav. arqueol., 1997, 3, 367-386.

SÁNCHEZ SÁNCHEZ, G. 2002: «Nuevos datos sobre el entorno del Arco de Trajano. Intervención arqueológica en un solar de la C/ Félix Valverde Lillo $n^{\circ}$ 9", Mérida, excav. arqueol., 2000, 6, 193-202.

Vargas Calderón, J. y Plasencia Sánchez, M. ${ }^{a}$ D. 2015: «Nuevas aportaciones al conocimiento arqueológico del entorno de la basílica de Santa Eulalia. Intervención arqueológica en el solar de la calle Cardero, $n^{0} 3$ (Mérida)», Mérida excav. arqueol. 2005, II, I57-I78.

Vivó, D., Palahí, Ll.; Nolla, J. M. a y Sureda, M. 2006: Aigua i conjunts termals a les civitates d'Emporiae, Gerunda i Aquae Calidae...sed vitam faciunt, Institut del Patrimoni Cultural de la Universitat de Girona, Girona.

YegüL, F. 20IO: Bathing in the Roman World, Cambridge University Press, New York. 


\section{Artículos · Articles}

13 Alfredo Cortell Nicolau

Ocre, hematites y óxido de hierro: el problema terminológico

Ochre, Hematite and Iron Oxid: The Terminological Issueu

43 Hipólito Pecci Tenrero

El Empleo de Armamento como elemento de aporte cronológico al arte rupestre Postpaleolítico del Cerro de San Isidro (Domingo García, Segovia) . The Use of Weapons as an Element of Chronological Contribution to the Post-Paleolithic Rock Art at the Cerro de San Isidro (Domingo García, Segovia)

67 SARA ARROYO CUADRA

Los narû (kudurrètu) babilónicos del Bronce Final y el Hierro

The Babylonian narû (kudurrētu) in Late Bronze and Iron Age

99 Silvia G.onzález Soutelo \& Sergio Vidal Álvarez \& Anna Gutiérrez Garcia-M. \& Hernando Royo Plumed

La placa de Amiadoso (Allariz, Ourense): Nuevos datos sobre el uso del mármol local en el noroeste de Hispania

The Amiadoso plaque (Allariz, Ourense): New Data from an Interdisciplinary Study about the Use of Local Marble in the NW of Hispania

\section{Ana Bejarano Osorio}

Contribución al estudio de los espacios termales de Augusta Emerita: el Balneum De La C/ Hernán Cortes y los modelos de doble alvei

Contribution to the Thermal Spaces of Augusta Emerita: the Balneum of C/ Hernán Cortés and the Double Models of alvei.

Arroyo del Pedroso II: un asentamiento visigodo en La Jara Cacereña

Arroyo del Pedroso II: A Visigoth Settlement in the Jara Cacereña 